Western University

Scholarship@Western

$11-26-2018$

\title{
Eyetracking of coarticulatory cue responses in children and adults
}

Alexandra M. Cross

The University of Western Ontario

Marc F. Joanisse

The University of Western Ontario, marcj@uwo.ca

Follow this and additional works at: https://ir.lib.uwo.ca/linguisticspub

Citation of this paper:

Cross, Alexandra M. and Joanisse, Marc F., "Eyetracking of coarticulatory cue responses in children and adults" (2018). Linguistics Publications. 6.

https://ir.lib.uwo.ca/linguisticspub/6 
Western\&Graduate\&PostdoctoralStudies

Western University

Scholarship@Western

Electronic Thesis and Dissertation Repository

7-23-2015 12:00 AM

Eyetracking of Coarticulatory Cue Responses in Children and Adults

Alexandra M. Cross

The University of Western Ontario

Supervisor

Marc Joanisse

The University of Western Ontario

Graduate Program in Psychology

A thesis submitted in partial fulfillment of the requirements for the degree in Master of Science

(C) Alexandra M. Cross 2015

Follow this and additional works at: https://ir.lib.uwo.ca/etd

Part of the Cognition and Perception Commons

\section{Recommended Citation}

Cross, Alexandra M., "Eyetracking of Coarticulatory Cue Responses in Children and Adults" (2015).

Electronic Thesis and Dissertation Repository. 2971.

https://ir.lib.uwo.ca/etd/2971

This Dissertation/Thesis is brought to you for free and open access by Scholarship@Western. It has been accepted for inclusion in Electronic Thesis and Dissertation Repository by an authorized administrator of

Scholarship@Western. For more information, please contact wlswadmin@uwo.ca. 


\title{
EYETRACKING OF COARTICULATORY CUE RESPONSES IN CHILDREN AND ADULTS
}

(Thesis format: Monograph)

by

\begin{abstract}
Alexandra M. $\underline{\text { Cross }}$
Graduate Program in Psychology

A thesis submitted in partial fulfillment of the requirements for the degree of Master of Science
\end{abstract}

The School of Graduate and Postdoctoral Studies

The University of Western Ontario

London, Ontario, Canada

(C) Alexandra M. Cross 2015 


\begin{abstract}
Studies examining sensitivity to coarticulatory cues during spoken word recognition have typically examined children and adults separately. The present thesis compared sensitivity to coarticulatory cues in school-aged children and adults using eyetracking. Children and adults listened to words containing congruent and incongruent coarticulatory cues while looking at a two-picture display. Contrary to theories positing weakened attention to phonetic detail in children, we observed equal or greater sensitivity to coarticulatory cues in children compared to adults. This effect was related to predictors of reading and language proficiency, and was also modulated by phoneme contrasts such that children were overly sensitive to more salient coarticulatory cues. These findings suggest that children are more sensitive to phonetic detail in speech than adults, and the phonological skills underlying this sensitivity are related to individual differences in reading and language ability.
\end{abstract}

\title{
Keywords
}

Language, spoken word recognition, coarticulation, eyetracking, development 


\section{Acknowledgements}

I would like to express my gratitude to all those who have been instrumental in the completion of this thesis. First and foremost, I would like to thank my supervisor, Dr. Marc Joanisse. His expertise and guidance have been invaluable to my experience as a graduate student and to the completion of this document. I am incredibly appreciative of the interest Marc has taken in my success, not only as a Masters student, but also in my future studies and career path. He has gone out of his way to open new doors for me, and I am truly looking forward to continuing to work with him.

Thank you also to the other primary investigators conducting the full-day kindergarten screening, Dr. Lisa Archibald, Dr. Janis Oram-Cardy, and Dr. Daniel Ansari, as well as their collaborators at the Thames Valley District School Board and the many research assistants who collected data for the project. The data collected during the screening has allowed me to explore my eyetracking data from new angles and in greater depth.

I would like to thank Kayla Perlmutter for her assistance and company while collecting data in schools. Thank you also to my fellow Joanisse lab members, Mikayla, Veronica, and especially Emily, for their feedback, guidance, and encouragement throughout my Masters.

Finally, I would like to thank my parents for being my practice audience and proofreaders, for their thoughtful questions and ideas, and for providing me with endless encouragement and support. 


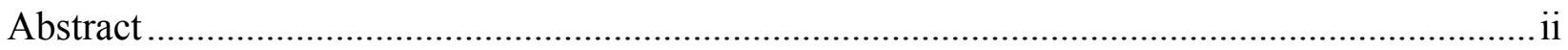

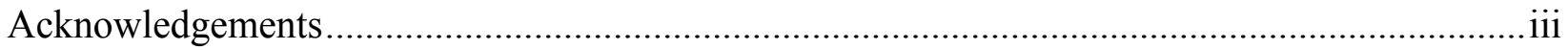

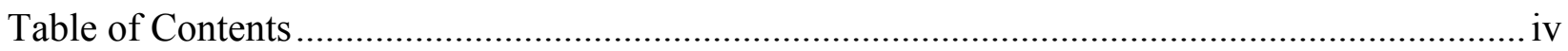

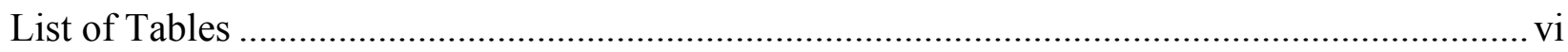

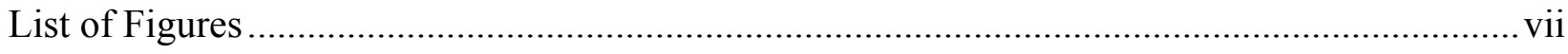

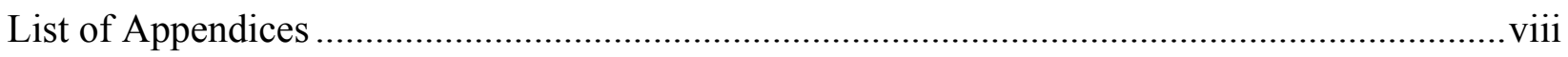

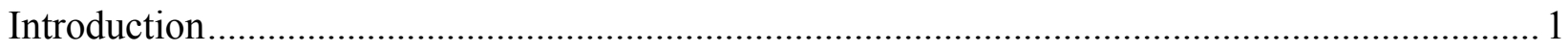

Sensitivity to coarticulatory cues in adults ……………….................................................... 1

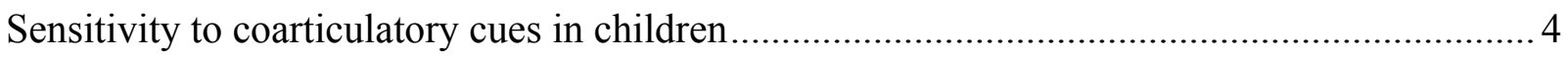

Coarticulatory cue sensitivity and reading and language proficiency ........................................ 6

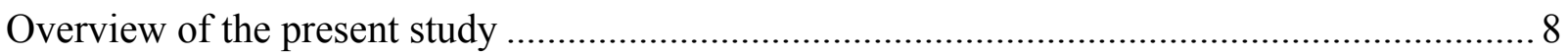

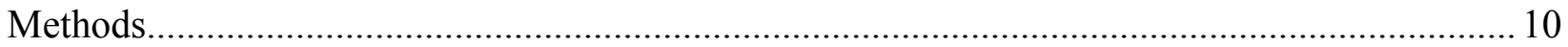

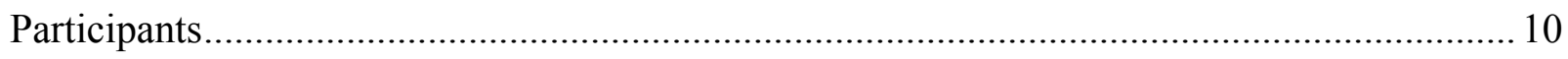

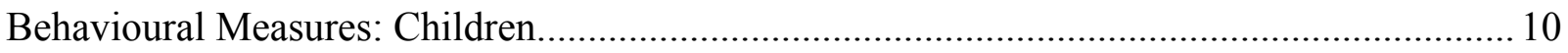

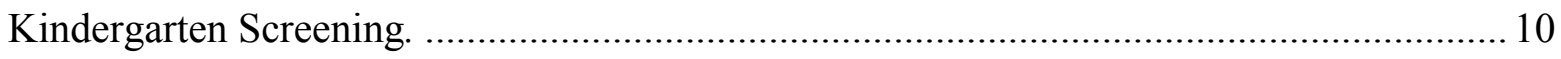

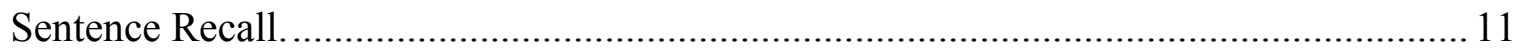

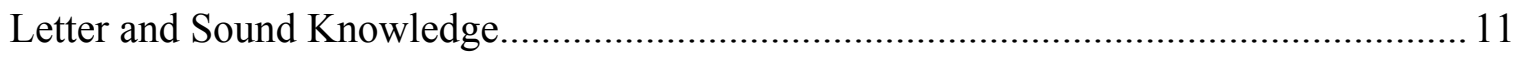

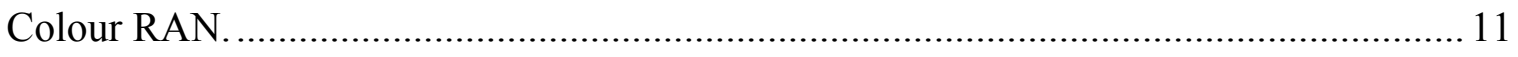

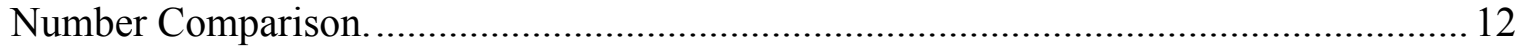

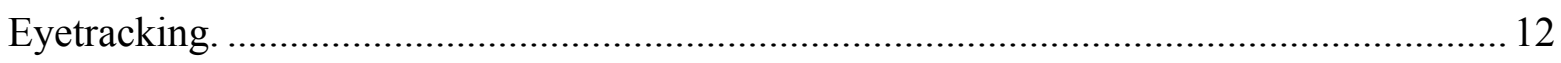

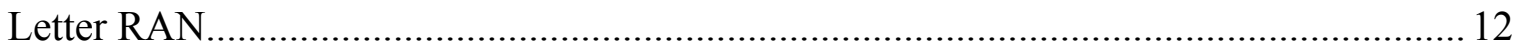




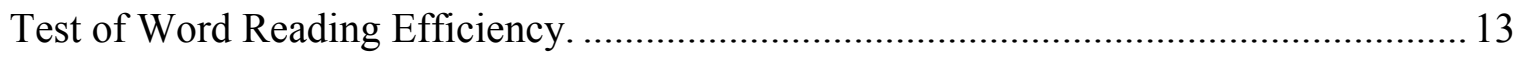

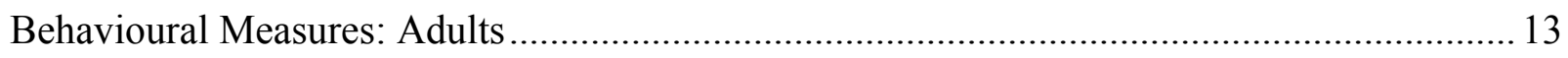

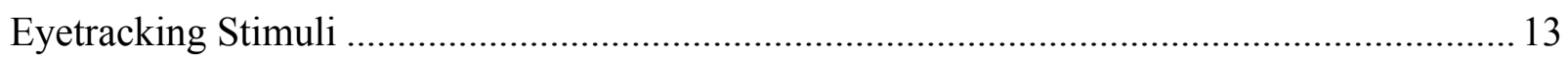

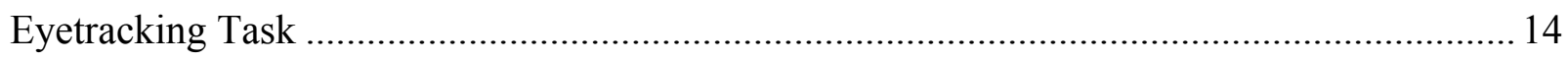

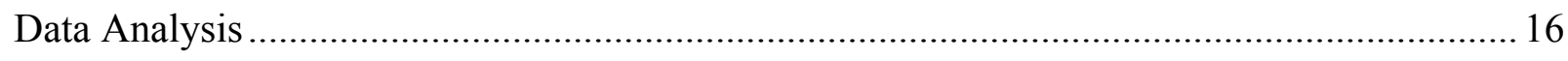

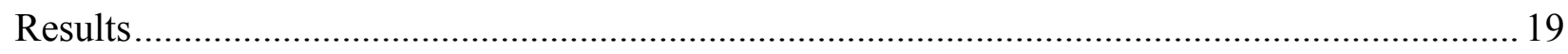

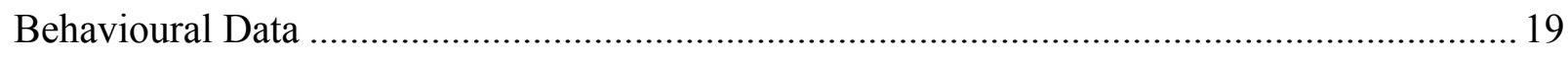

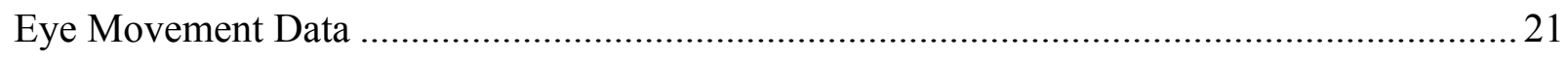

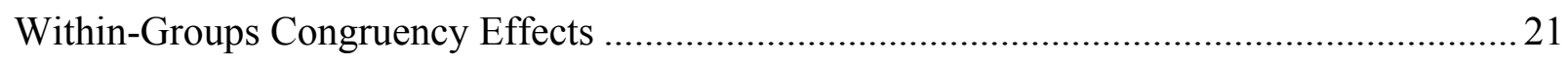

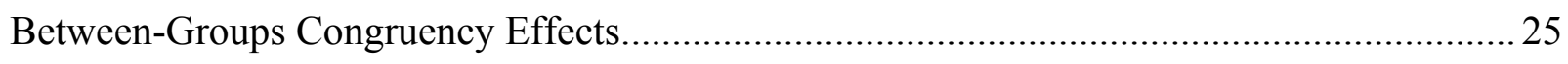

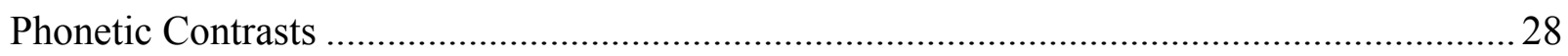

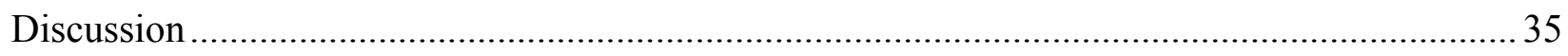

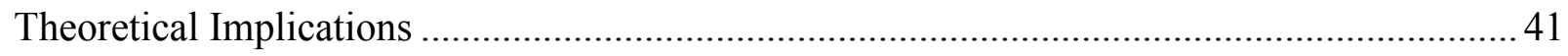

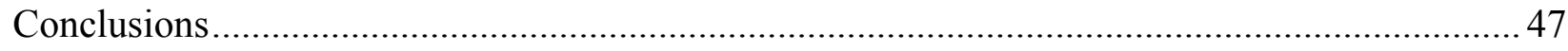

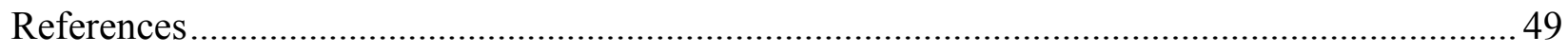

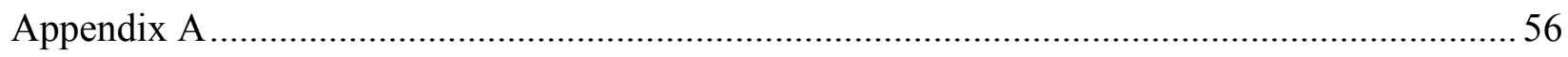

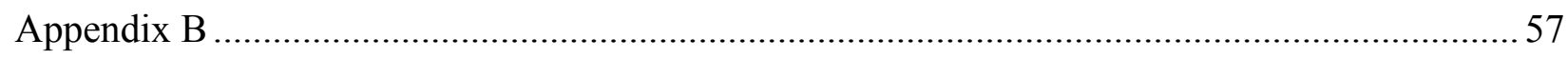

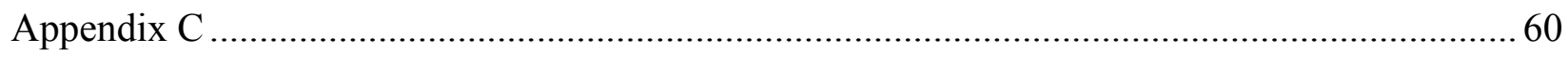

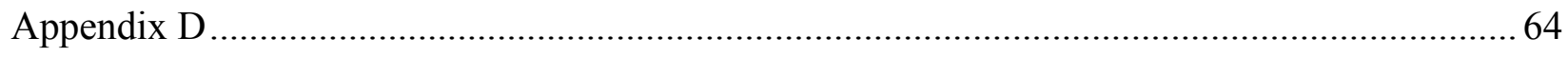

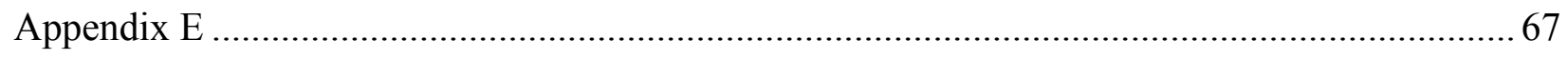

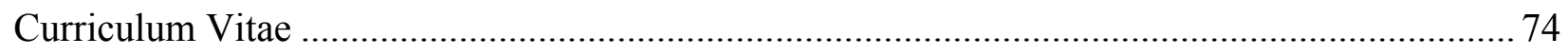




\section{List of Tables}

Table 1. Descriptive statistics for behavioural tasks............................................................... 19

Table 2. Behavioural measures during the eyetracking tasks............................................ 20

Table 3. Parameter estimates for growth curve analysis within groups. ................................. 25

Table 4. Parameter estimates for growth curve analysis between groups. ...............................28

Table 5. Correlations among behavioural measures. .............................................................. 31

Table 6. Correlation of growth curve parameter estimates with behavioural measures in children. 


\section{List of Figures}

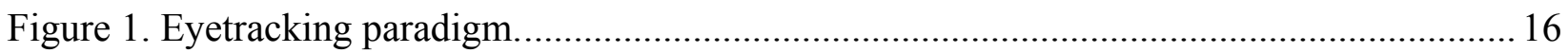

Figure 2. Growth curve analysis of looks to the target picture in each group. ..........................23

Figure 3. Growth curve analysis of looks to the competitor picture in each group.................... 24

Figure 4. Growth curve analysis of difference curves compared between groups.....................227

Figure 5. Growth curve analysis of difference curves by phoneme and group. ........................... 30

Figure 6. jTRACE simulation of target word activation................................................... 45

Figure 7. jTRACE simulation of competitor word activation. .............................................. 45 


\section{List of Appendices}

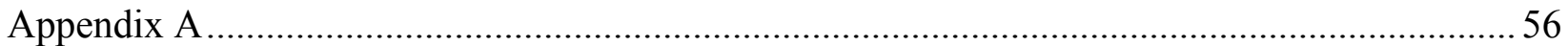

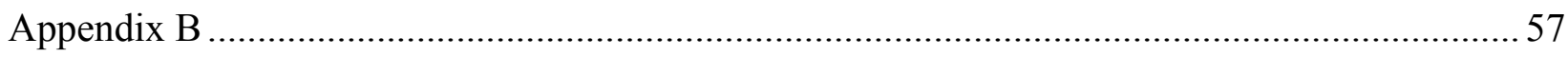

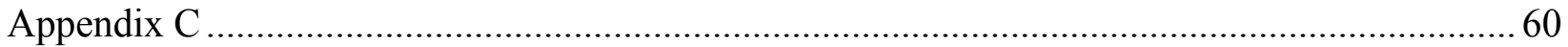

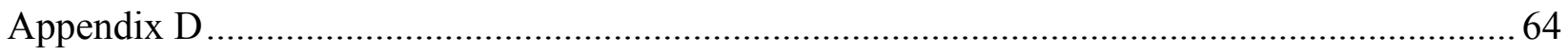

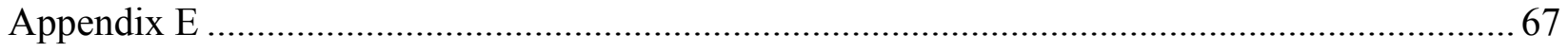


Eyetracking of coarticulatory cue responses in children and adults

Successful spoken word recognition requires online integration of acoustic speech input with previously learned knowledge of words and sounds. Variability is ubiquitous in spoken language, complicating the process of spoken word recognition. The acoustic properties of speech can vary based on physical characteristics of speakers, the acoustic environment in which the utterance is produced, and the linguistic context of the utterance. A major source of variability in speech derives from coarticulation, where the articulation of each phoneme is influenced by the articulatory features of surrounding phonemes (LaRiviere, Winitz, \& Herriman, 1975a; LaRiviere, Winitz, \& Herriman, 1975b; Blumstein \& Stevens, 1980). Consequently, the acoustic characteristics of speech sounds are realized differently in different contexts. Coarticulatory cues can also be carried to varying degrees depending on the coarticulated phoneme and its neighbours (Stevens \& House, 1963; Bladon \& Al-Bamerni, 1976). This variability contributes to the lack of invariance in speech. However, some of this variability is systematic, which allows listeners to use coarticulatory information to predict upcoming speech sounds or disambiguate lexical competitors (Liberman, Cooper, Shankweiler, \& Studdert-Kennedy, 1967; Marslen-Wilson \& Warren, 1994; Norris, McQueen, \& Cutler, 2000).

\section{Sensitivity to coarticulatory cues in adults}

Early studies of spoken word recognition suggest that speakers abstract phonemic information from speech input to eliminate phonetic detail prior to lexical recognition (Forster, 1976). However, more recent empirical findings have provided evidence that adults are sensitive to fine-grained phonetic information during spoken word recognition. For example, McMurray, Tanenhaus, and Aslin (2002) manipulated spoken words to vary in the initial consonant's voice onset time (VOT), and observed that eye movements to the VOT competitor picture increased as 
the stimulus neared the VOT boundary between phonemes. These findings suggest that the systematic variability of sub-phonemic features such as voicing plays an important role in efficient spoken word recognition.

Similarly, research has demonstrated that adults use the systematicity of sub-phonemic coarticulatory information during speech recognition, such that recognition of a word is improved when appropriate coarticulatory cues are present and weakened when incongruent cues are artificially inserted into the speech stream. For example, Marslen-Wilson and Warren (1994) presented participants with a gating task, in which successive segments of a word are presented and the participant is asked to identify the word at each gate. In this particular gating task, stimuli were cross-spliced so that some words contained incongruent coarticulatory cues. On trials with incongruent stimuli, participants took more gates to correctly identify the word. The authors suggest that listeners predict certain coarticulatory cues in context and this is used to access words and rule out competitors, resulting in slowed lexical access and increased competition in the presence of incongruent information. Similar congruency effects have also been demonstrated in word identification tasks (Mitterer \& Blomert, 2003) and lexical decision tasks (McQueen, Norris, \& Cutler, 1999). Sensitivity to coarticulatory violations is also reflected in electrophysiological responses; adults demonstrate event-related potential responses to incongruent coarticulatory cues in prelexical but not lexical stages of processing (Archibald \& Joanisse, 2011), indicating that subphonemic detail is used during prelexical processing but does not constrain lexical processing. This suggests that coarticulatory information is used in speech segmentation and spoken word recognition.

The larger part of early research examining the use of coarticulatory cues used offline tasks, such as gating or word recognition tasks measuring reaction time, providing little insight 
into the time course and processes leading up to recognition of a spoken word. A growing body of research has used eyetracking paradigms to provide more time-sensitive and nuanced insight into the process of spoken word recognition. In the visual world paradigm, participants view a display of multiple objects, and their eye movements are tracked as they listen to auditory speech input (Tanenhaus, Spivey-Knowlton, Eberhard, \& Sedivy, 1995). The linking hypothesis has related the time course of eye movements to each object on the display to the mental processes underlying auditory word recognition (Tanenhaus, Magnuson, Dahan, \& Chambers, 2000). For example, Allopenna, Magnuson, and Tanenhaus (1998) measured the time course of lexical activation of competitors matched to the target on the initial phoneme or rhyme. Participants heard instructions such as "Pick up the beaker" while an eyetracker recorded eye movements to the target object (i.e. a beaker), a cohort competitor matched on the initial phoneme (i.e. a beetle), a rhyme competitor (i.e. a speaker), and an unrelated competitor (i.e. a carriage). Eye movements to the target and to the cohort competitor increased after $200 \mathrm{~ms}$, suggesting that eye movements reflect lexical activation from word onset. Allopenna et al. also replicated the pattern of eye movements using the TRACE model of spoken word recognition (McClelland \& Elman, 1986) and linked the time course of the model's lexical activation to lexical activation in real time, providing compelling evidence of the link between eye movements and processing of linguistic input in real time.

With respect to coarticulation, eyetracking research has provided evidence that lexical activation in adults depends on phonetic detail, and not only on an abstraction of phoneme categories. Dahan, Magnuson, Tanenhaus, and Hogan (2001) monitored eye movements to a picture display in response to stimuli with congruent and incongruent coarticulatory cues. The stimuli with congruent coarticulatory cues contained the word onset from the target word (e.g., 
$n e^{t} t$, while stimuli with incongruent coarticulatory cues contained word onset from a familiar word (e.g., $\left.n e^{c k} t\right)$ or from a nonword (e.g., $n e^{p} t$ ). Participants viewed a display of four pictures: three of phonologically unrelated words and one that matched the target word, and eye movements to the target picture were measured from word onset. When incongruent coarticulatory cues came from a familiar word, fixations to the target picture were slowed. Although incongruent coarticulatory cues from nonwords resulted in a slight slowing effect, fixations to the target in this condition demonstrated a pattern more similar to the fixations observed in the congruent coarticulation condition. This pattern was subsequently simulated with the TRACE model. These results suggest that adults are sensitive to subtle phonetic detail during lexical access, and lexical competition leads to a greater disruption in lexical access when the phonetic mismatch matches a familiar word than when it matches a nonword.

\section{Sensitivity to coarticulatory cues in children}

It remains unclear whether the process of lexical access in children makes use of the same sources of information as adults. The speed and accuracy of spoken word recognition increases from early childhood to adulthood (Garlock, Walley, \& Metsala, 2001), which could be attributed to changes in how words are represented or to changes in how spoken words are processed.

First, a developmental increase in efficiency of spoken word recognition could be explained by the developmental trajectory of lexical representation: in order to cope with a growing vocabulary, representations must become increasingly segmented or phonologically detailed (Walley, 1993; Elbro, 1996; Hurtado, Marchman, \& Fernald, 2007). With respect to coarticulatory cues, this would be expected to lead to increased sensitivity to coarticulatory information as lexical representations become more phonetically detailed. However, research has demonstrated that in infants these representations are at least well-specified enough to allow 
sensitivity to incongruent consonants and vowels. For example, 14 month olds (Swingley \& Aslin, 2002) and 18-23 month olds (Swingley \& Aslin, 2000) were able to detect phonemic mismatches when object labels contained consonant or vowel mispronunciations (i.e. babyvaby; apple - opple), and this effect was unrelated to vocabulary size. The authors suggest children's early representations are phonetically well-specified, even in children with small vocabularies.

Alternately, efficiency of spoken word recognition may be improved as children learn what aspects of the acoustic signal are most important to speech processing. Research has suggested that adults assign different perceptual weights to acoustic properties of speech, such as coarticulatory information, and these weights vary based on how salient those acoustic properties are in a given phonetic environment (Dorman, Studdert-Kennedy, \& Raphael, 1977). Nittrouer and Miller (1997) extended this research to children, and demonstrated that the weights assigned by children to a given acoustic property differed less across phonetic environments than weights assigned by adults. The authors suggested that children had not yet learned the relationship between the informativeness of an acoustic property and its phonetic environment. Over time, children may learn when coarticulatory cues are important during word recognition, leading to faster spoken word recognition with more efficient perceptual weighting of acoustic information.

The current literature on children's sensitivity to phonetic detail has focused on phonemelevel mispronunciations, such that children's sensitivity to more subtle phonetic detail is largely unexamined. It remains unclear whether children encode coarticulatory information in lexical representations, or whether they make use of coarticulatory information in same manner as adults do during spoken word recognition. The present study aimed to examine sensitivity to 
incongruent coarticulatory information in children and adults, to explore spoken word recognition and phonetic specification of lexical representations during childhood and adulthood.

Behavioural evidence suggests that children are able to use overlapping phonetic cues in speech. In a study of nonword repetition, typically developing 10-year-old children were able to repeat syllable sequences more accurately when they were presented as a single coarticulated nonwords (i.e. fowmoychee) than when they were presented in serial (fow... moy... chee) (Archibald \& Gathercole, 2007) or in nonwords with invalid coarticulation (Archibald, Gathercole, \& Joanisse, 2009), suggesting children used coarticulatory cues during processing and encoding of the stimuli. However, little research has examined children's sensitivity to coarticulatory information using time sensitive measures, and it remains unclear whether children perceive and process coarticulatory cues in the same manner as adults. In addition, the overwhelming majority of existing studies of coarticulatory cues have focused on comparisons of typically developing children to atypical populations. Research by Archibald and Joanisse (2012) suggested that 10-year-old children showed similar electrophysiological responses to incongruent coarticulation as the responses observed in adults in the Archibald and Joanisse (2011) study, but no research to date has directly compared coarticulatory sensitivity in children and adults. In order to provide a more fine-grained comparison of the process of spoken word recognition in children and adults, the present study used eyetracking to explore children and adults' use of coarticulatory information during speech processing and their encoding of phonetic detail in lexical representations.

\section{Coarticulatory cue sensitivity and reading and language proficiency}

The use of phonetic information during spoken word recognition may also be related to reading and oral language proficiency, although most existing research has focused on atypically 
developing groups rather than examining a broad spectrum of individual differences. With respect to speech perception, difficulties in phoneme categorization and discrimination have been observed in children with dyslexia relative to typical readers (Manis et al., 1997; Werker \& Tees, 1987). However, evidence of these difficulties is not always statistically robust, and studies that account for other aspects of language suggest that speech perception deficits may only be present in a subset of children with dyslexia who also display broader language impairments (Joanisse, Manis, Keating, \& Seidenberg, 2000). Children with dyslexia also appear to show poor auditory word recognition performance as measured by gating tasks (Bruno et al., 2007), however this study made use of congruent articulation only and inferred that children who were more sensitive to congruent coarticulatory cues would be able to identify words in earlier gates. Given that no incongruent coarticulatory cues were used in this study, and that these findings are somewhat unusual (e.g., see Griffiths \& Snowling, 2001), it remains unclear whether coarticulatory sensitivity differs based on reading proficiency.

Deficits in speech perception are more commonly and robustly observed in children with oral language difficulties. Archibald and Gathercole (2007) examined nonword repetition in children with specific language impairment (SLI), and suggested that the disproportionate deficit in nonword repetition once short-term memory was accounted for may be a result of difficulty using speech cues such as prosody and coarticulation. Event-related potentials in response to incongruent coarticulatory cues demonstrated atypical neural responses in prelexicalphonological stages of processing in children with SLI (Archibald \& Joanisse, 2012), suggesting that children with language difficulties are less sensitive to phonetic detail in speech than typically developing children. 
While studies have suggested that coarticulatory cue sensitivity differs in children with SLI, and possibly dyslexia, it remains unclear whether this sensitivity relates to reading or language proficiency in the general population. The present study examined the relationship of coarticulatory cue responses to early predictors of language and reading in children to explore whether the kinds of phonological skills measured by responses to coarticulation are related to proficiency in reading, language, or both, in a broad sample of children with a variety of reading and language abilities.

\section{Overview of the present study}

The purpose of the present study was to examine using eyetracking whether coarticulatory cue responses differ in school-aged children and adults. Given substantial evidence that eye movements reflect the time course of lexical activation, eyetracking provides a means of examining the time course of spoken word recognition and lexical activation in the presence of phonetic violations. Children and adults completed a picture-word matching task while their eye movements were measured in response to spoken word stimuli. Stimuli were cross-spliced to contain congruent and incongruent coarticulatory cues in the initial consonant. Eye movements to target and competitor pictures were then analyzed using a Growth Curve Analysis (GCA) approach (Mirman, Dixon, \& Magnusson, 2008), a multilevel regression technique that allows analysis of time course data while modeling both group-level and individual-level effects. This technique modeled the time course of eye movements as a whole rather than breaking data into multiple discrete time steps, providing high temporal resolution without compromising statistical power. The coarticulation condition and group variables were included as terms in the model, permitting the examination of coarticulatory effects and whether these differed between children and adults. 
Based on previous literature, we expected to find a congruency effect in both groups. This would suggest, in line with previous studies of phonetic detail in lexical representations, that both children and adults encode lexical representations with phonetic detail. Different degrees of sensitivity to coarticulatory information in children and adults could speak to differences in the specificity of their lexical representations, or to differences in the use of phonetic information during spoken word recognition. If lexical representations become increasingly detailed or segmented with increased experience with speech during childhood, adults should demonstrate a larger congruency effect, reflecting their more phonetically detailed lexical representations. However, it is also possible that adults, who have likely encountered more variability in speech than children, are slightly less responsive to coarticulatory variability to allow efficient lexical access despite omnipresent variability in speech.

Because coarticulatory cues vary in their salience, varying congruency effects were expected between phoneme contrasts. Additionally, children's lesser degree of experience with speech may lead to increased sensitivity to salient coarticulatory cues, which would result in an interaction of the congruency effect between phoneme contrasts and age group.

Finally, the importance of phonetic processing in reading and language suggests that congruency effects should also be related to reading and language proficiency. The children participating in this study also participated in a screening of early childhood learning one year prior to the current study, allowing the examination of how sensitivity to coarticulation relates to reading, language and cognitive development. Correlations were expected between congruency effects and children's pre-reading and language scores from the screening, as well as their performance on measures of reading development completed during the current study. No 
relationship between measures of mathematics and sensitivity to coarticulation was expected given that mathematical processing does not rely on phonetic processing.

\section{Methods}

\section{Participants}

Participants were 51 neurologically healthy native speakers of English, recruited from the London, Ontario community. Nineteen (13 female) were adults aged $21 ; 0$ to $30 ; 0(\mathrm{M}=24 ; 1$, SD $=2 ; 6)$ recruited via word of mouth. Twenty-nine $(21$ female) were children aged $6 ; 0$ to $7 ; 0(\mathrm{M}=$ 6;7 $\mathrm{SD}=0 ; 4)$ enrolled in Grade 1 in schools in the London, Ontario area. These children had participated in a screening of early reading, language, and mathematics predictors in kindergarteners between 9 and 12 months prior to their participation in the current study, and were recruited by phone and through their schools. Three additional children were recruited but were not included in analyses as they were unable to successfully complete at least fifty percent of eyetracking trials. All child and adults subjects reported normal hearing and normal or corrected-to-normal vision.

Testing sessions were approximately 30 minutes long. Adults were tested in a quiet room at the University of Western Ontario and were compensated for their time. Informed consent was obtained from each adult participant prior to testing. Children were tested in quiet rooms at their school and were given a sticker for their participation. Parents gave informed consent prior to the testing sessions, and verbal assent was obtained from children before testing. This study was approved by the University of Western Ontario Research Ethics Board.

\section{Behavioural Measures: Children}

Kindergarten Screening. Between nine and twelve months prior to testing for the current study, children participated in a screening of early childhood learning which was conducted in a 
larger sample of 183 senior kindergarten students. They completed a battery of tests examining early predictors of reading, language, and mathematics abilities. The measures of interest to the current study are described in more detail below.

Sentence Recall. During the sentence recall task (see Appendix A), participants listened to 16 sentences over headphones and were asked to repeat each sentence. Each sentence was scored with 2 points if all words were repeated correctly, 1 if three or fewer errors were made, and 0 if the sentence was repeated with four or more errors. A total sentence recall score out of 32 was calculated for each child, and this was converted to a percentage score. The sentence recall task was used here because it has been shown to be a good predictor of broader language abilities in children (Archibald \& Joanisse, 2009).

Letter and Sound Knowledge. Letter and sound knowledge, which is associated with later reading skill (Bond \& Dykstra, 1967; Scarborough, 1998), was measured by asking participants to identify the name and sound of each letter of the English alphabet (see Appendix B). Participants were shown two randomized lists of uppercase and lowercase letters, and were asked to name the sound associated with each letter. First, sound identification trials were presented, and each trial was scored as correct if the sound was a possible phoneme-grapheme pair in English, to yield a total possible score out of 52. After identifying sounds for the upper- and lowercase lists, participants named each letter on both lists. The letter knowledge task was also scored out of 52 based on correct naming of each upper- and lowercase letter. A composite percentage score was calculated based on performance on both letter naming and sound naming tasks.

Colour RAN. Rapid Automatized Naming (RAN) is a predictor of reading fluency and accuracy (Denckla \& Rudel, 1976; Bowers \& Wolf, 1993). During the colour RAN task, participants 
viewed an array of 50 coloured boxes (see Appendix C). Participants were asked to name the colour of each box as quickly and accurately as possible. Performance was scored based on the number of colours correctly identified per second.

Number Comparison. The number comparison task (Nosworthy et al., 2013) is a predictor of mathematics achievement. During this task, participants were shown two boxes, each containing an Arabic numeral ranging from one to nine. Participants were asked to identify which box contained a number of a larger magnitude. Participants were presented with 56 trials and completed as many comparisons as possible in two minutes. The task was scored based on the number of correct number comparisons completed per second.

Eyetracking. A subset of children from the original screening study were next invited to the eyetracking study based on their performance on the screening's reading and language predictors. This included 18 children from the lowest $15 \%$ of scores on one or more of the sentence recall, letter and sound knowledge, and RAN tasks as well as 32 children who performed within one standard deviation of the sample mean on all three measures, to ensure a distribution of reading and language abilities which captured both low and average scores. The final sample of participants included 8 children from the lowest $15 \%$ of scores and 21 children whose scores were within one standard deviation of the mean.

During testing for the current study, children also completed behavioural measures of mathematics and reading. Some of these were part of a different study and are not reported here. The measures of interest to the current study are described below.

Letter $\boldsymbol{R} \boldsymbol{A} N$. An additional RAN task was administered during the testing session. The letter RAN task consisted of a 50-item array of the letters $g, k, l$, and $m$ repeated in randomized order 
(see Appendix D). Participants were asked to name the items as quickly and accurately as possible, and the task was scored based on the number of items correctly named per second. Test of Word Reading Efficiency. The Test of Word Reading Efficiency (TOWRE) (Torgesen, Wagner, \& Rashotte, 1999) is a standardized measure of reading fluency and accuracy, consisting of two subtests. The Sight Word Efficiency subtest is a list of 104 words, while the Phonemic Decoding Efficiency subtest consists of 64 pronounceable nonwords. Participants were asked to read each list as quickly and accurately as possible in 45 seconds. Each subtest was scored based on the number of items read correctly in 45 seconds, and raw scores converted to standardized scores based on age-based norms.

\section{Behavioural Measures: Adults}

During the testing session, adult participants also completed the TOWRE as a measure of reading fluency and accuracy. The Sight Word and Phonemic Decoding subtests of the TOWRE were both administered as described above, and scores on each subtest were converted to agebased standardized scores.

\section{Eyetracking Stimuli}

The visual and auditory stimuli were drawn from stimuli in Archibald \& Joanisse (2011). The visual stimuli were ten colour stock photos matched to auditory stimuli. The pictures were all 400 pixels in width and varied from 267 to 425 pixels in height. Pictures were presented on a white background. The auditory stimuli consisted of digitally re-spliced monosyllabic English $\mathrm{CV}$ and CVC words, beginning with the consonants $/ \mathrm{f} /, / \mathrm{h} /, / \mathrm{m} /, / \mathrm{f} /$, and $/ \mathrm{t} \mathrm{f} /$. Words were paired, based on their initial consonant, with a second word differing in the place of articulation in the subsequent vowel. Each word stimulus was recorded four times by three different female speakers at 16 bits and a sample rate of $22,050 \mathrm{~Hz}$. The recordings were spliced using Sound 
Forge 6.0 (Sonic Foundry Inc., 2002) by identifying the point of transition between the initial consonant and vowel and editing the stimuli at this point.

All word stimuli were cross-spliced within speakers such that the word initial consonant contained a congruent or incongruent coarticulatory cue with respect to the following vowel. For example, the $/ \mathrm{m} /$ from a token of mat was respliced onto /un/ from a token of moon recorded from the same speaker, to create the incongruent stimulus $m^{a}$ oon. Congruent stimuli were also cross-spliced to account for any effects of the splicing procedure. For example, the $/ \mathrm{m} /$ from a token of moon was respliced onto/un/ from another token of moon recorded by the same speaker, to create the congruent stimulus $m^{u}$ oon. These stimuli were paired with pictures matching either valid or invalid coarticulatory cues. On half of the trials, the spoken word contained a valid coarticulatory cue to the picture matching the word. The second picture matched only the first consonant of the spoken word. On the other half of the trials, the word matched a picture but contained an invalid coarticulatory cue matching the second picture.

In adults, stimuli consisted of ten monosyllabic words, paired based on the word initial consonant: feed-phone, hand-hoop, mat-moon, chew-cheese, sheep-shoe. This was reduced to three monosyllabic word pairs in children: feed-phone, hand-hoop, mat-moon. We chose these pairs for children based on the items from the adult data that demonstrated the clearest effects of incongruency. The number of stimuli was reduced in children in order to decrease the number of trials without reducing the number of presentations of each word.

\section{Eyetracking Task}

Both groups of participants completed a picture-word matching task while their eye movements were measured on a Tobii T120 Eye Tracker, with stimuli presented using E-Prime software (Psychology Software Tools, Inc., Sharpsburg, PA). Data were collected at $60 \mathrm{~Hz}$ in the 
adult group, and at $120 \mathrm{~Hz}$ resampled to $60 \mathrm{~Hz}$ in children. Visual stimuli were presented on the eyetracker's 17-inch TFT monitor. In adults, auditory stimuli were presented through two computer speakers placed on either side of the eyetracker. On-ear headphones were used during testing of children to ensure that they could hear the auditory stimuli despite variability in the noise levels in testing spaces available at schools.

During the eyetracking task (see Figure 1), participants first viewed a blank white display for $1000 \mathrm{~ms}$. Two pictures were then presented on either side of the display for $1000 \mathrm{~ms}$. The two pictures remained on the display while a green fixation circle was presented at the center of the screen. Participants were instructed to fixate on the circle. Once the participants fixated on the circle for $200 \mathrm{~ms}$, a spoken word was presented and eye movements to both the target and competitor picture were measured from the onset of the word. On each trial, participants were asked to answer which picture matched the word using a button press. Responses and reaction times were recorded on each trial.

Prior to the experiment, the eyetracker was calibrated to the participant's eye movements. Next, adult participants completed 180 trials, half containing congruent auditory stimuli and half containing incongruent auditory stimuli; children completed 108 trials of the eyetracking task, half containing congruent and half containing incongruent stimuli. In both children and adults, each word was presented a total of 18 times: nine times with congruent coarticulation, and nine times with incongruent coarticulation. In addition, trials for the children were divided into two even-sized blocks, allowing children to take a break from the task part-way. The RAN letters and the two RAN numbers tasks were administered after the first block of 54 eyetracking trials. Children completed the TOWRE Sight Word Efficiency and Phonemic Decoding Efficiency subtests following the eyetracking task. 


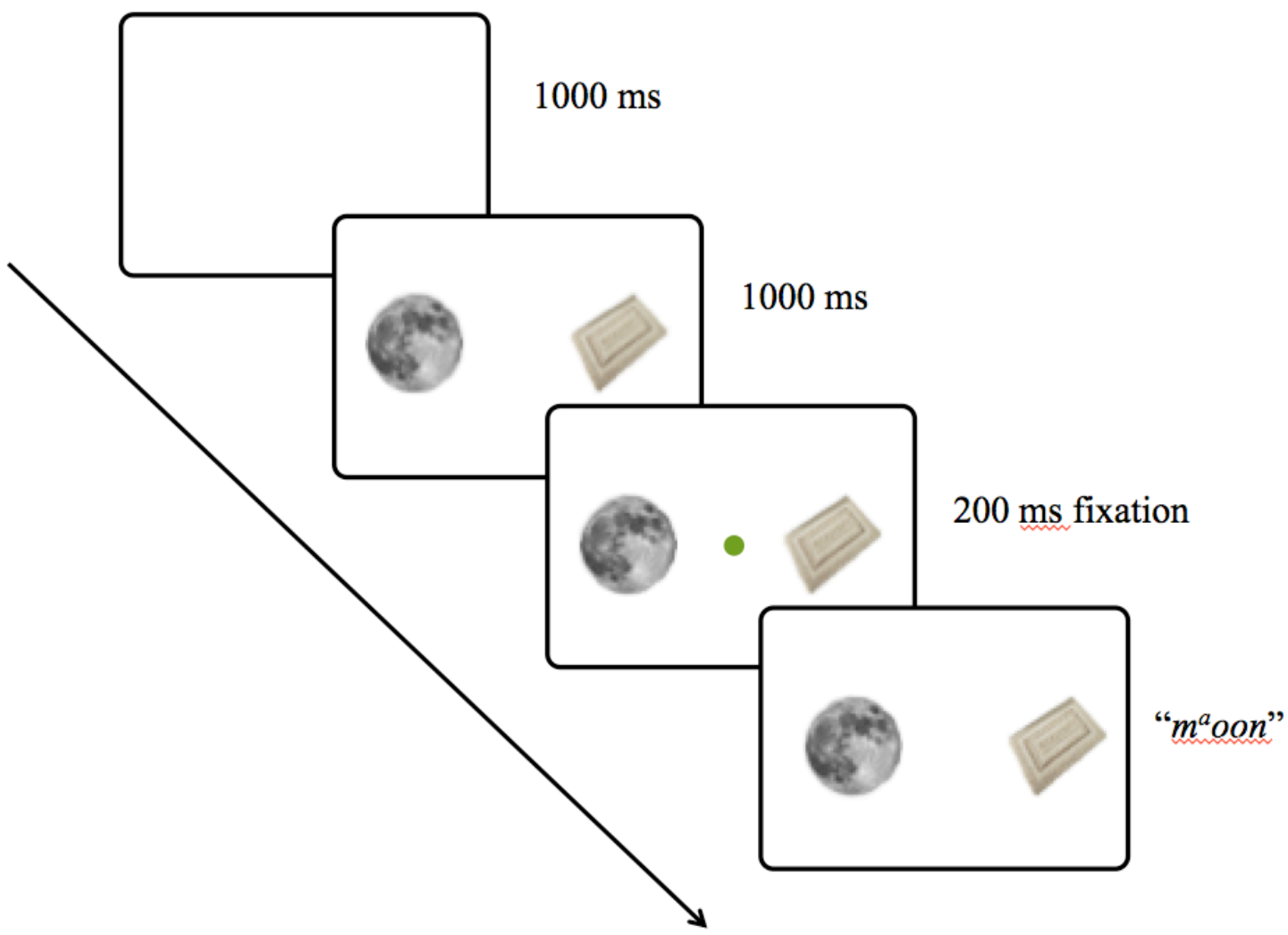

Figure 1. Eyetracking paradigm. Following 200ms of fixation on the green circle, the word was played and eye movements to the target (moon) and competitor (mat) pictures were measured.

\section{Data Analysis}

Eyetracking data were analyzed as follows: the number of looks to the target picture, competitor picture, fixation circle, and other regions of the display were computed for each time point. The proportion of looks to each picture was calculated by dividing the number of looks to the target or competitor picture by the total number of looks. The proportion of looks to the target picture and to the competitor picture were analyzed using a Growth Curve Analysis (GCA) technique (Mirman, 2014) to compare between coarticulatory conditions and between groups. 
GCA is a multilevel regression technique used to model change over time. It allows modeling of time course data without the need to either compare data across multiple time bins or average these time bins together, both of which can obscure temporal effects. This technique can incorporate both group-level and individual-level differences into the model. Here, the time variable was modeled using an orthogonal polynomial, which captures the curvature of the data and is orthogonally transformed to avoid collinearity of higher order polynomials. Conditions and groups are compared by adding group-level or individual differences, stepwise, to each polynomial term of the GCA model, and using an analysis of variance (ANOVA) to compare whether adding the variable to each polynomial term significantly improves the model's fit. Additionally, the parameter estimates are compared between conditions or between groups to examine differences in the shape of the data. Significant differences in the intercept term represent different means, while differences in the linear term of the model are associated with different slopes. The quadratic and cubic terms of the model represent its curvature, and significant differences in these terms can be interpreted as different quadratic and cubic curvatures between conditions or groups.

For each group, the proportion of looks to the target picture was examined using a logistic GCA. A logistic GCA allowed the model to capture the asymptotic nature of proportional data. The coarticulatory condition variable was added to the model as a fixed effect, to examine whether the model's fit was significantly improved and the model's parameters were significantly different with the addition of the condition variable. To examine the proportion of looks to the competitor picture, data were modeled using GCA with condition added as a fixed effect.

Difference curves were also calculated for each group in order to compare congruency effects between children and adults using GCA. For each subject, the proportion of looks in the 
incongruent condition at each time point was subtracted from the proportion of looks in the congruent condition. The resulting two difference curves for the proportion of looks to the target picture and to the competitor picture represent the congruency effect, or the distance between the curves for the congruent and incongruent conditions. Calculating the difference between conditions allowed us to normalize the overall proportion of looks for each participant before examining congruency effects, in order to account for possible differences in the degree to which the two groups tend to fixate to both pictures. GCA was used to compare the difference curves for each picture between groups, in order to examine whether the congruency effect differed between children and adults.

Congruency effects for the individual phonetic contrasts were also investigated using GCA. Difference data for the target and for the competitor were first compared for the phonemes $/ \mathrm{f} /, / \mathrm{m} /$, and $/ \mathrm{h} /$ by performing a GCA within each group, adding the phoneme variable as a fixed effect to the model. Group was then added as a fixed effect to the model to examine whether the phonetic contrast variable interacted with the group variable.

To examine whether congruency effects were related to behavioural measures in children, difference curves for target and competitor looks were modeled for each subject individually, and parameter estimates for the intercept, linear, quadratic, and cubic parameter terms were extracted. These were then correlated with behavioural measures using a Pearson correlation. Specifically of interest were the relationships of congruency effects to the behavioural measures of sentence recall, letter and sound knowledge, colour RAN, letter RAN, TOWRE Sight Word Efficiency, and TOWRE Phonemic Decoding Efficiency. The number comparison task, a behavioural measure of mathematical ability completed during the kindergarten screening, was also included as a general measure of learning. Since mathematical ability is not expected to be related 
independently to speech perception, correlation of congruency effects to the number comparison measures along with the other behavioural measures may suggest that coarticulatory sensitivity is related to childhood learning in general rather than reading and language specifically.

\section{Results}

\section{Behavioural Data}

Descriptive statistics for the behavioural reading, language, and mathematics measures are provided in Table 1. In addition, TOWRE subtests scores are included for the adult sample. TOWRE scores are standardized scores calculated using age-based norms, while all other behavioural measures are presented as raw scores.

Table 1. Descriptive statistics for behavioural tasks.

\begin{tabular}{|c|c|c|c|c|}
\hline & \multicolumn{2}{|c|}{ Children } & \multicolumn{2}{|c|}{ Adults } \\
\hline & Mean & SD & Mean & $\mathrm{SD}$ \\
\hline Age (years:months) & $6 ; 7$ & $0 ; 4$ & $24 ; 1$ & $2 ; 6$ \\
\hline Sentence Recall (\%) & 59.1 & 26.0 & - & - \\
\hline Letter/Sound Knowledge (\%) & 90.3 & 16.0 & - & - \\
\hline Colour RAN (\#correct/sec) & 0.81 & 0.26 & - & - \\
\hline Number Comparison (\#correct/sec) & 0.33 & 0.09 & - & - \\
\hline TOWRE Sight Word & 104.2 & 14.2 & 101.3 & 11.76 \\
\hline TOWRE Phonemic Decoding & 105.9 & 12.2 & 106.4 & 12.0 \\
\hline Letter RAN (\#correct/sec) & 1.09 & 0.26 & - & - \\
\hline
\end{tabular}


Percent accuracy and mean reaction time on button press responses in the eyetracking task are provided in Table 2. Only trials with correct responses were included in the calculation of mean reaction time. A 2x2 mixed model ANOVA with congruency as the within-subjects factor (congruent vs. incongruent) and group as the between-subjects factor (children vs. adults) demonstrated there were no main effects of congruency $(F(1,45)=0.008, p=.93)$ and of group $(F(1,45)=2.532, p=.12)$ on percent accuracy. A second $2 \times 2$ mixed model ANOVA was performed to examine reaction time, showing an interaction of congruency and group $((F(1,45)$ $=5.097, p<.05)$ and a main effect of group $(F(1,45)=49.56, p<.01)$, but no significant main effect of congruency $(F(1,45)=0.128, p=.72)$. Children responded significantly more slowly on congruent trials than incongruent trials, while there was no difference in response times by congruency in adults.

Table 2. Behavioural measures during the eyetracking tasks. Values represent the mean percent accuracy and mean reaction time for the button press response. Values in parentheses represent standard error.

\begin{tabular}{lccccc}
\hline & \multicolumn{2}{c}{ Percent accuracy } & & \multicolumn{2}{c}{ Reaction time (ms) } \\
\cline { 2 - 3 } \cline { 5 - 5 } Condition & Children & Adults & & Children & Adults \\
\hline Congruent & $97.1(0.97)$ & $99.4(0.18)$ & & $1770.2(101.1)$ & $747.8(19.5)$ \\
& & & & & \\
Incongruent & $97.0(1.36)$ & $99.4(0.19)$ & & $1602.4(114.1)$ & $771.7(19.7)$ \\
\hline
\end{tabular}




\section{Eye Movement Data}

\section{Within-Groups Congruency Effects}

The observed looks to the target picture and to the competitor were first analyzed independently within each group, using growth curve analysis (GCA) to examine congruency effects in children and in adults. Eye movements were analyzed from word onset to the point at which a maximum proportion of looks to the picture were reached. This upper limit was chosen to capture the average reaction time of the sample as well as the asymptote of looks to the target picture. Observed data and model fits for the congruent and incongruent conditions within each group are plotted in Figure 2. The estimated parameters for the fitted model in each group are provided in Table 3 .

A base model was first created containing only the effects of time and subjects. The congruency variable was then added into the model as a fixed effect, and the model was constructed in a stepwise fashion adding congruency to the linear, quadratic, and cubic terms of the model to determine its effect on each component. At each step, the model fit was assessed using an analysis of variance to examine whether including the effect of congruency in the model improved fit. Once the fit of the full model had been assessed, parameter estimates were generated and tested using $t$-tests to assess the significance of their impact on the model's components.

The observed proportion of looks to the target picture in children and adults was examined using a logistic GCA, which captures the asymptotic nature of the target fixation data. Analysis for children was performed between 0 and $1000 \mathrm{~ms}$, at which time point the maximum proportion of looks to the target was reached. In children, the addition of congruency improved model fit on the intercept $\left(\chi^{2}(1)=122.39, p<.01\right)$ and cubic terms $\left(\chi^{2}(1)=7.33, p<.01\right)$. 
These significant changes in deviance represent improvements in the model's fit with respect to the mean proportion of looks and cubic curvature of the model. Significant differences in the parameter estimates were also observed in all terms of the model, indicating that the mean proportion of looks, slope, quadratic curvature, and cubic curvature of the model differed significantly between the congruent and incongruent conditions. With respect to eye movements, this represents fewer and slowed looks to the target picture in children on incongruent trials (see Figure 2).

Likewise, a similar analysis of looks to the target picture in adults from 0 to $800 \mathrm{~ms}$ showed improved model fit with the addition of congruency to the linear $\left(\chi^{2}(1)=35.01, p<.01\right)$ and cubic terms $\left(\chi^{2}(1)=41.60, p<.01\right)$. The improvement in model fit suggests that the addition of congruency to the model accounted for some additional variance in the slope and curvature of eye movements. The estimated parameters differed significantly between congruency conditions, suggesting that the mean proportion of looks, slope, and curvature of the models differed in the incongruent condition compared to the congruent condition. These results suggest the presence of a congruency effect in which adult participants looked less at and more slowly towards the target picture when given incongruent coarticulatory information (see Figure 2). 

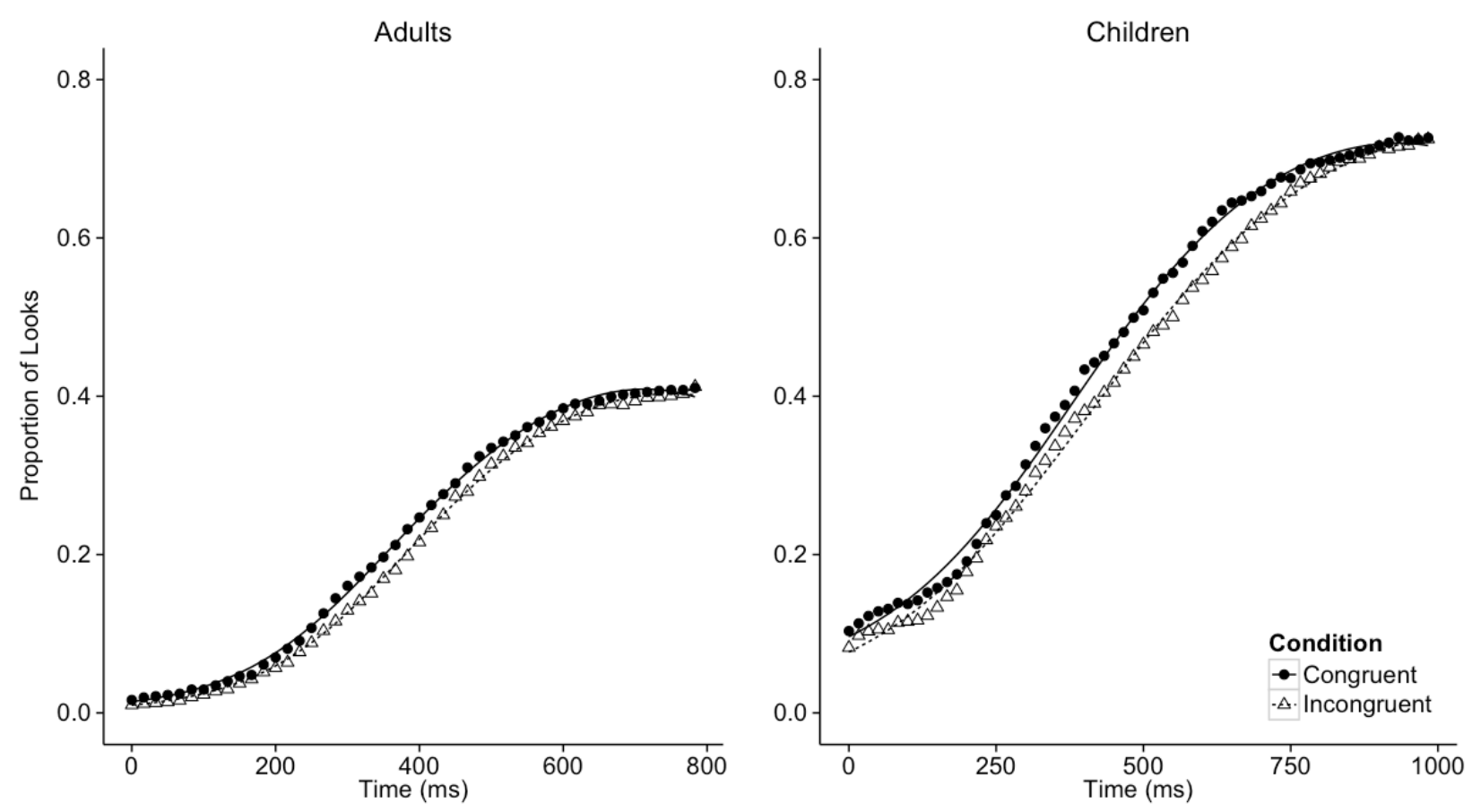

Figure 2. Growth curve analysis of looks to the target picture in each group. Symbols represent the observed data and lines represent the fitted models.

The proportion of looks to the competitor was also examined using GCA with congruency added stepwise to the base model. Looks to the competitor picture were examined from word onset to $1200 \mathrm{~ms}$ in children. Adding the congruency variable improved model fit on the intercept $\left(\chi^{2}(1)=7.45, p<.01\right)$, linear $\left(\chi^{2}(1)=196.31, p<.01\right)$, quadratic $\left(\chi^{2}(1)=4.14, p<\right.$ $.05)$, and cubic terms $\left(\chi^{2}(1)=14.82, p<.01\right)$. Additionally, the parameter estimates for the intercept, quadratic, and cubic terms differed significantly in children (see Table 3). With respect to children's eye movements, these results can be interpreted as representing a congruency effect in which the proportion of looks to the competitor reached a higher and sharper maximum in the incongruent condition, as demonstrated in Figure 3. This suggests that children fixated more 
quickly, for a longer duration, and to a greater degree, to the competitor picture when presented in incongruent coarticulatory information.

In adults, a similar pattern of results suggests the presence of a congruency effect in the pattern of eye movements to the competitor picture. Model fit from 0 to $800 \mathrm{~ms}$ was increased with the addition of condition to the linear $\left(\chi^{2}(1)=12.79, p<.01\right)$ and cubic terms $\left(\chi^{2}(1)=\right.$ $107.33, p<.01)$, and the parameters estimates were significantly different between conditions for the intercept, linear, and quadratic terms. The significant intercept term represents a higher overall proportion of looks to the competitor picture in the incongruent condition, while the linear term and quadratic term represent a faster rate of fixation and a deeper peak of proportion of looks at the maximum curve. Accordingly, these results confirm the observation in Figure 3 that adults fixated more quickly and to a greater degree to the competitor picture on incongruent trials.
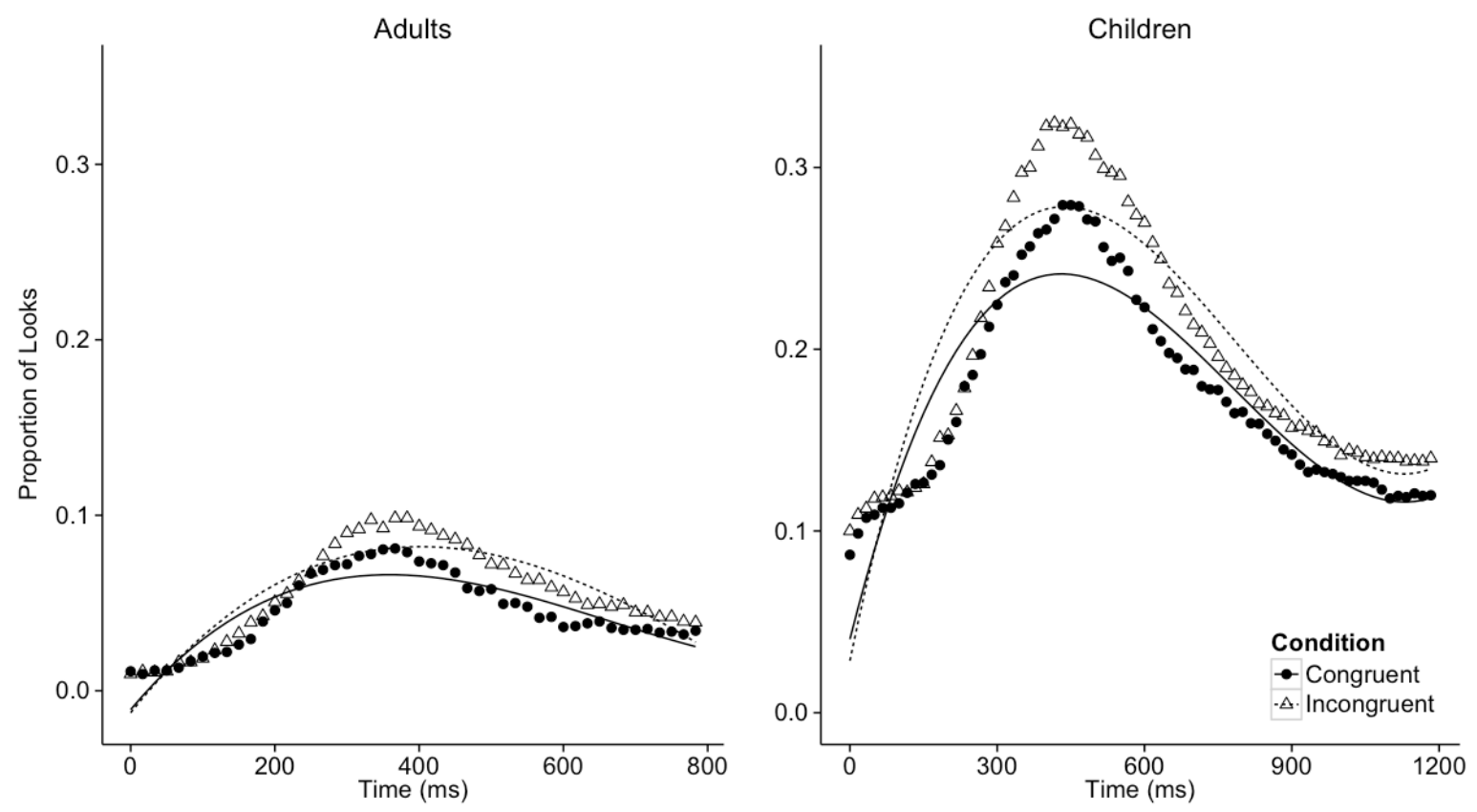

Figure 3. Growth curve analysis of looks to the competitor picture in each group.Symbols represent the observed data and lines represent the fitted models. 
Table 3. Parameter estimates for growth curve analysis within groups.

\section{Looks to Target}

\begin{tabular}{|c|c|c|c|c|c|c|}
\hline & \multicolumn{3}{|c|}{ Children } & \multicolumn{3}{|l|}{ Adults } \\
\hline & Est. & $z$ & $p<$ & Est. & $z$ & $p<$ \\
\hline Intercept & 3.33 & 2.017 & .05 & 8.27 & 3.626 & .01 \\
\hline Linear & 49.69 & 2.168 & .05 & 121.30 & 3.715 & .01 \\
\hline Quadratic & 26.39 & 2.233 & .05 & 67.99 & 3.786 & .01 \\
\hline Cubic & 6.25 & 2.247 & .05 & 19.42 & 3.963 & .01 \\
\hline \multicolumn{7}{|c|}{ Looks to Competitor } \\
\hline & \multicolumn{3}{|c|}{ Children } & \multicolumn{3}{|l|}{ Adults } \\
\hline & Est. & $t$ & $p<$ & Est. & $t$ & $p<$ \\
\hline Intercept & 0.12 & 2.218 & .05 & -0.47 & -2.247 & .05 \\
\hline Linear & 1.65 & 1.911 & n.s. & -6.77 & -2.273 & .05 \\
\hline Quadratic & 1.17 & 2.282 & .05 & -3.52 & -2.209 & .05 \\
\hline Cubic & 0.56 & 3.789 & .01 & -0.73 & -1.867 & n.s. \\
\hline
\end{tabular}

\section{Between-Groups Congruency Effects}

The within-groups analyses above indicated that a congruency effect was present in both children and adults. Subsequent analyses compared the magnitude of the congruency effect between children and adults, by computing target and competitor difference curves. These were calculated by subtracting the incongruent from the congruent proportion of looks at each time point for each individual. The resulting target and competitor difference curves were compared using GCA, in which the group variable was added stepwise to the base model as a fixed effect. 
The estimated parameters were tested for significance to examine the group variable's contribution to the model's components. The observed difference data and corresponding model fits are plotted in Figure 4, and the estimated parameters for the fitted model are provided in Table 4.

Looks to the target picture were modeled from word onset to $1100 \mathrm{~ms}$. Here, a larger congruency effect would typically be manifested as a larger difference curve upwards and higher or broader peak, corresponding to a larger difference in the magnitude of fixation proportion between conditions. Adding the group variable to the model improved fit on the cubic term $\left(\chi^{2}\right.$ $(1)=35.95, p<.01)$. The intercept, linear, quadratic, and cubic parameters differed significantly between groups (see Table 4). The significant intercept term represents a smaller overall difference in fixations in children, and the linear term indicates that difference curves for children had more negative slope. Although these terms both suggest that the congruency effect was smaller in children, this may be a result of variability in the tails of the data, which are less relevant to early congruency effects at the onset of word stimuli. The significant quadratic term represents a sharper curvature in adults, suggesting that the difference in fixations in children had a broader peak. As shown in Figure 4, this suggests that the difference between conditions is slightly larger in children than in adults, representing a larger response to coarticulatory incongruency in children.

Because difference curves were generated by subtracting the incongruent condition from the congruent condition, the congruency effect for eye movements to the competitor picture yielded a negative-going difference curve as shown in Figure 4. Looks to the competitor picture were examined from word onset to $1000 \mathrm{~ms}$. Adding the group variable increased the model fit on the intercept $\left(\chi^{2}(1)=34.40, p<.01\right)$ and quadratic terms $\left(\chi^{2}(1)=7.84, p<.05\right)$, suggesting 
that the group variable accounted for additional variance in the mean difference in the proportion of looks. Because adding the group variable to the cubic term did not significantly improve model fit, the quadratic model's parameter estimates were examined for differences between groups. Significance tests of the quadratic model's estimated parameters yielded no significant differences. These results suggest that although the group variable accounted for additional variance beyond that of the base model, there were no between-group differences in congruency effects for looks to the competitor picture.
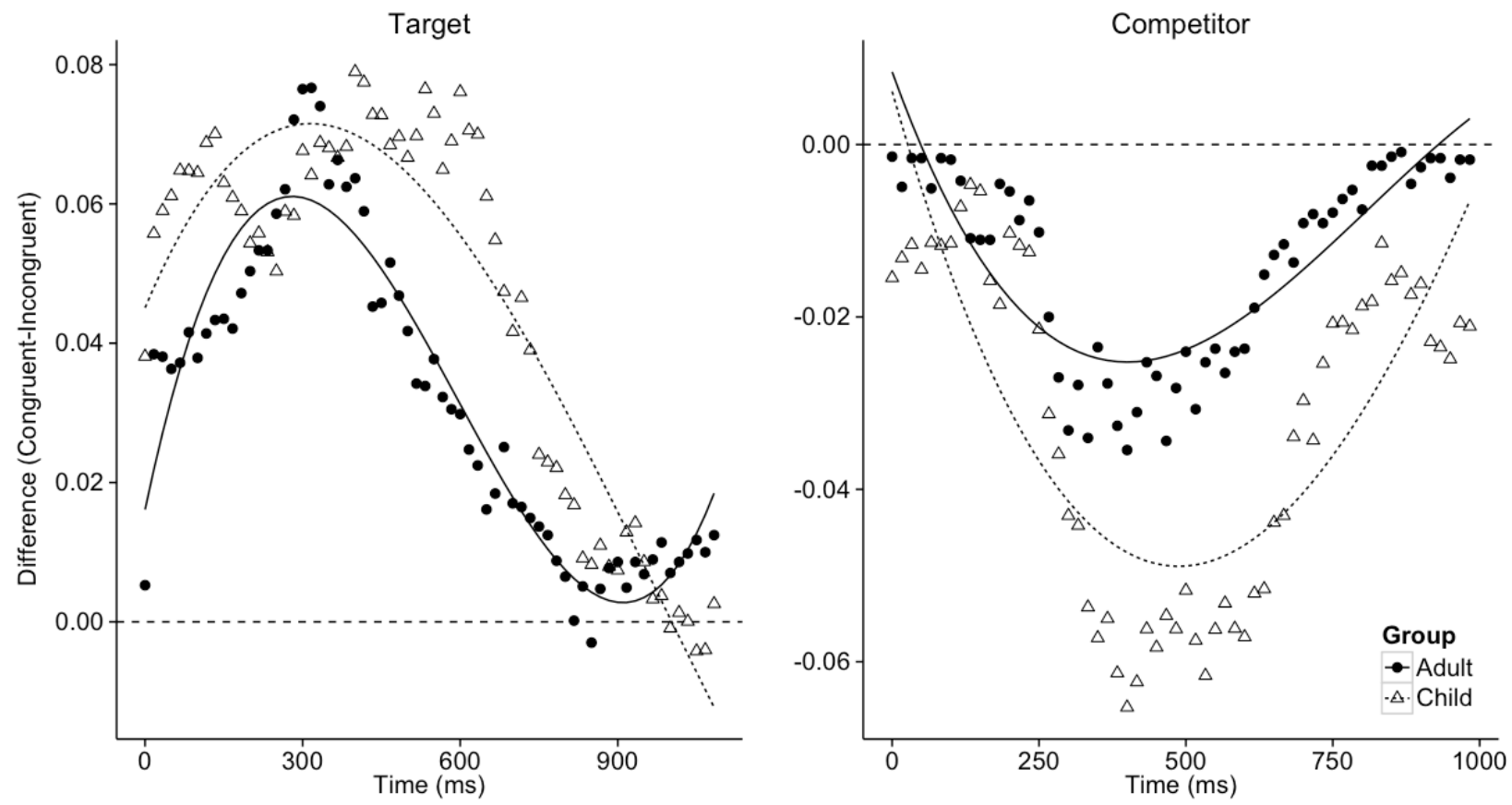

Figure 4. Growth curve analysis of difference curves compared between groups. Symbols represent the observed data and lines represent the fitted models. 
Table 4. Parameter estimates for growth curve analysis between groups.

\begin{tabular}{lcccccccc}
\hline & \multicolumn{3}{c}{ Target Difference Curves } & & \multicolumn{3}{c}{ Competitor Difference Curves } \\
\cline { 2 - 3 } \cline { 7 - 9 } & Est. & $t$ & $p<$ & & Est. & $t$ & $p<$ \\
\hline Intercept & -0.53 & -3.70 & .01 & & 0.08 & 0.657 & n.s. \\
Linear & -8.03 & -3.71 & .01 & & 1.37 & 0.806 & n.s. \\
Quadratic & -4.66 & -3.34 & .01 & & 0.62 & 0.886 & n.s. \\
Cubic & -1.27 & -2.67 & .01 & & - & - & - \\
\hline
\end{tabular}

\section{Phonetic Contrasts}

To examine whether congruency effects differed between phoneme contrasts /f/, /h/, and $/ \mathrm{m} /$, difference curves were modeled with the group and phoneme variables added as fixed effects. Here, the group variable was added on all terms to create a base model, and the phoneme variable was added stepwise to the model to examine its interaction with the group variable. Difference curves were analyzed from 0 to $1000 \mathrm{~ms}$ post stimulus onset. This range was chosen as the point at which congruent and incongruent data converged following the maximum looks to target. Figure 5 shows the observed difference curves and model fits by group and phoneme for eye movements to the target picture and to the competitor picture.

As shown in Figure 5, congruency effects for looks to the target picture appear larger for the phonemes $/ \mathrm{h} /$ and $/ \mathrm{m} /$ compared to $/ \mathrm{f} /$. This observation is supported by the results of the GCA, in which adding the phoneme variable significantly improved model fit on the intercept $\left(\chi^{2}\right.$ $(2)=288.74, p<.01)$, linear $\left(\chi^{2}(2)=74.24, p<.01\right)$, quadratic $\left(\chi^{2}(2)=24.20, p<.01\right)$, and cubic $\left(\chi^{2}(2)=55.80, p<.01\right)$ terms. Parameter estimates differed significantly between the 
phoneme $/ \mathrm{f} /$ and the phoneme $/ \mathrm{h} /$ for the intercept $(t=-2.03, p<.05)$, linear $(t=-2.08, p<.05)$, and quadratic terms $(t=-2.03, p<.05)$, as well as between the phoneme $/ \mathrm{f} /$ and the phoneme $/ \mathrm{m} /$ for the intercept $(t=2.11, p<.05)$, linear $(t=2.11, p<.05)$, and quadratic terms $(t=2.15, p<$ $.05)$. These results suggest that across groups, eye movements reflected larger congruency effects in both groups for phonemes $/ \mathrm{h} /$ and $/ \mathrm{m} /$, in which the differences between conditions were larger in magnitude, rose more steeply, and had a greater degree of curvature than for the phoneme /f/. No significant interaction of the group and phoneme variables was observed in the parameter estimates. This suggests that although eye movements differed by phoneme type, the congruency effect demonstrated similar patterns by phoneme in adults and children.

The competitor difference curves were examined for group and phoneme effects and interactions in a similar manner. The addition of the phoneme variable increased model fit on the intercept $\left(\chi^{2}(2)=217.70, p<.01\right)$, linear $\left(\chi^{2}(2)=65.20, p<.01\right)$, and cubic $\left(\chi^{2}(2)=119.06, p<\right.$ $.01)$ terms, indicating that this variable accounted for additional variance beyond the base model. Across both groups, the phonemes $/ \mathrm{h} /$ and $/ \mathrm{m} /$ differed significantly from $/ \mathrm{f} /$ on the intercept $(t=$ $2.57, p<.05 ; t=-2.04, p<.05)$, linear $(t=-2.57, p<.05 ; t=-2.06, p<.05)$, quadratic terms $(t=-$ $2.60, p<.01 ; t=-2.10, p<.05)$, and cubic terms $(t=-2.64, p<.01 ; t=-2.08, p<.05)$. The phoneme and group variables demonstrated an interaction, in which the phoneme $/ \mathrm{h} /$ in children had significantly different parameter estimates for the intercept $(t=2.01, p<.05)$, linear $(t=2.08$, $p<.05)$, and quadratic terms $(t=2.09, p<.05)$. As illustrated in Figure 5 , the difference curve for the phoneme $/ \mathrm{h} /$ in children had a larger negative-going slope, a lower peak, and a larger curvature, representing a larger congruency effect in children for the phoneme $/ \mathrm{h} /$ compared to other phonemes and compared to the adult group. 
Target

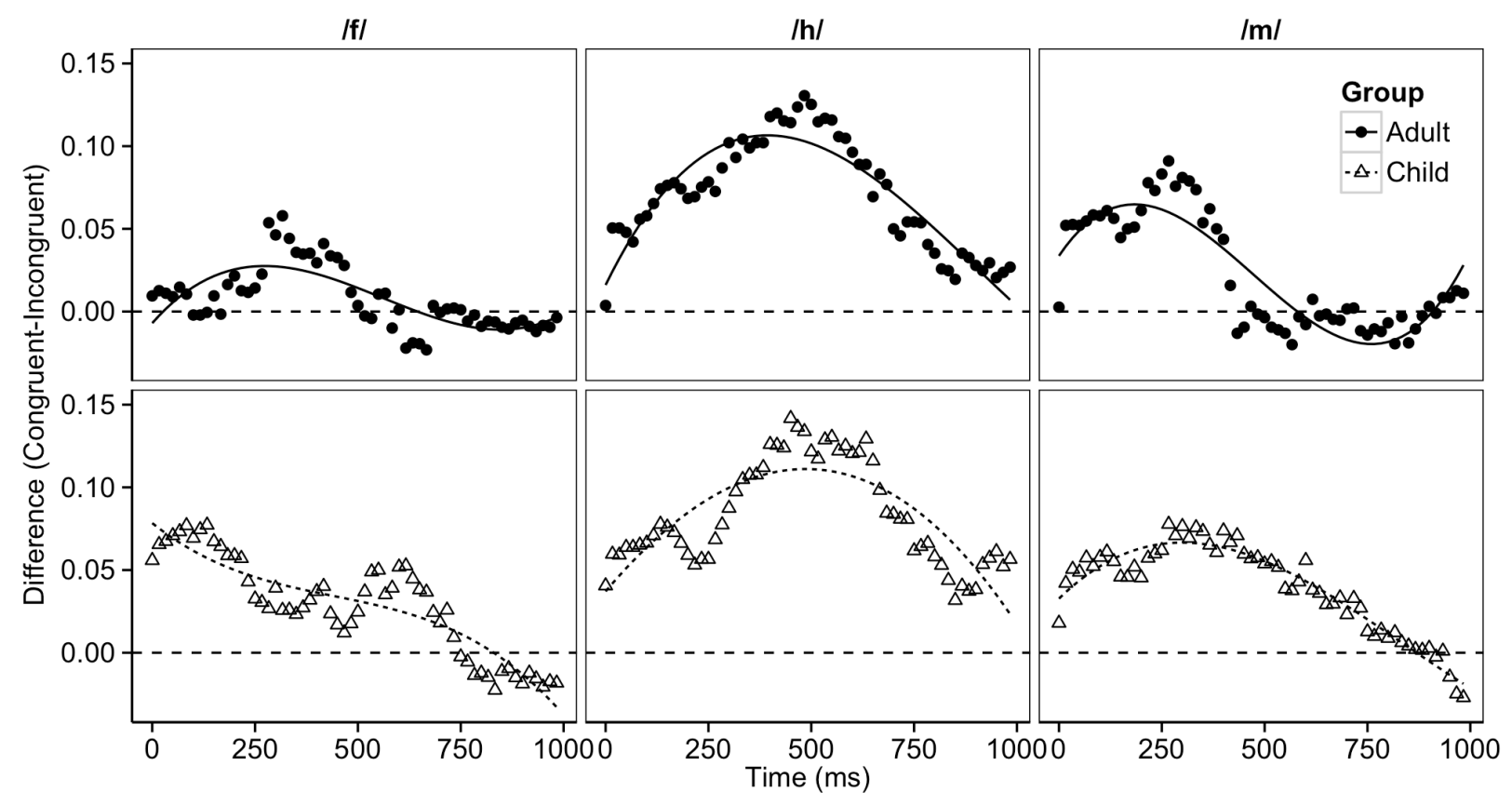

Competitor

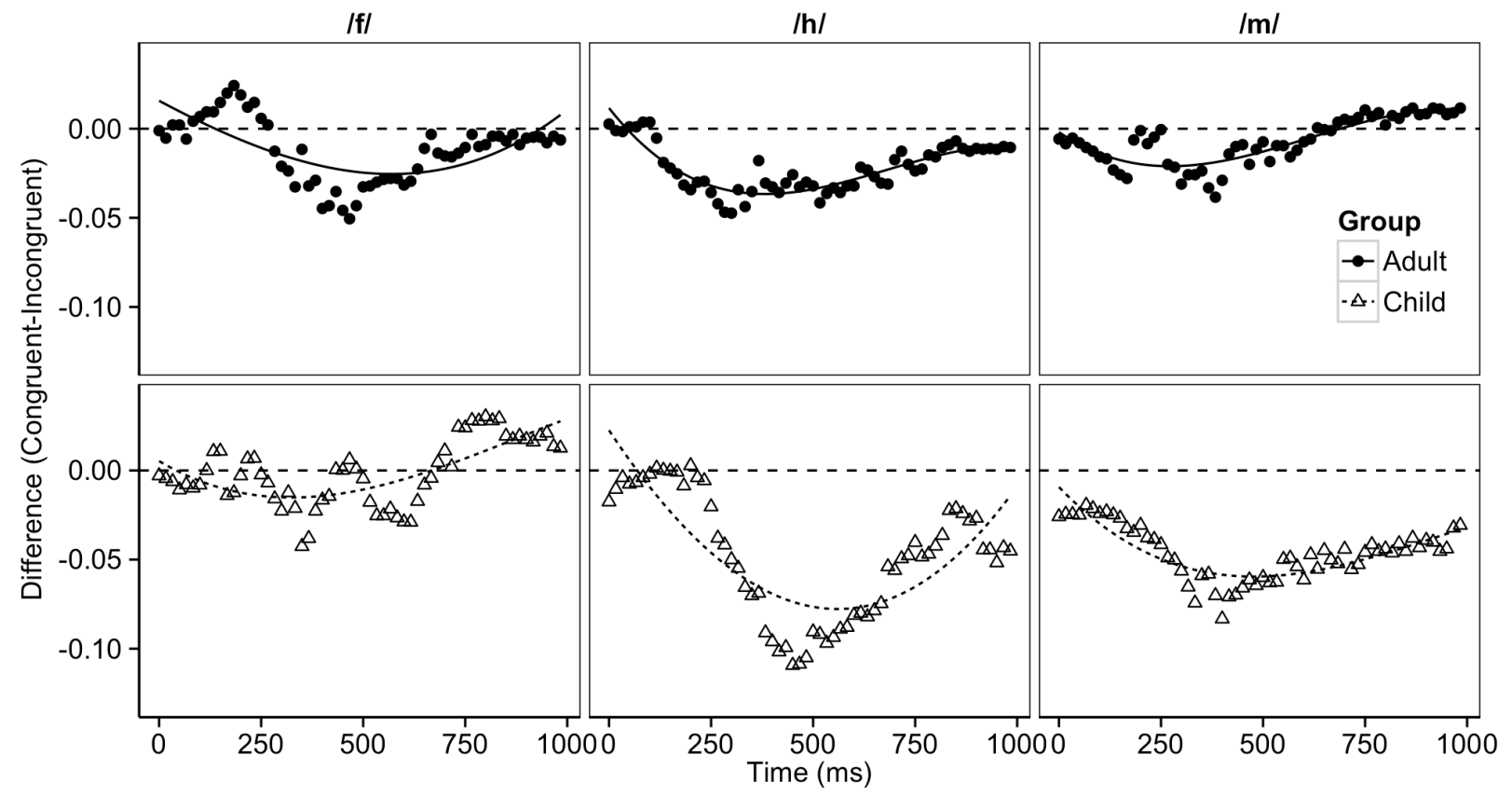

Figure 5. Growth curve analysis of difference curves by phoneme and group. Symbols represent the observed data and lines represent the fitted models. 


\section{Behavioural Correlates of Congruency Effects}

Finally, we examined whether children's responses to coarticulatory mismatch related to behavioural measures of language and cognitive development. First, correlations among these measures were analyzed using Pearson correlations. The correlation matrix is presented in Table 5.

Table 5. Correlations among behavioural measures.

\begin{tabular}{|c|c|c|c|c|c|c|c|c|}
\hline & & 1 & 2 & 3 & 4 & 5 & 6 & 7 \\
\hline 1 & Sentence Recall & - & 0.23 & 0.09 & $0.64 * *$ & $0.48 * *$ & $0.41 *$ & 0.32 \\
\hline 2 & Letter/Sound Knowledge & & - & -0.22 & $0.52 * *$ & 0.12 & 0.10 & $0.66 * *$ \\
\hline 3 & Colour RAN & & & - & 0.18 & $0.41 *$ & 0.35 & 0.11 \\
\hline 4 & Number Comparison & & & & - & $0.41 *$ & $0.38 *$ & $0.63 * *$ \\
\hline 5 & TOWRE Sight Word & & & & & - & $0.87 * *$ & $0.55 * *$ \\
\hline 6 & TOWRE Phonemic Decoding & & & & & & - & 0.40 \\
\hline 7 & Letter RAN & & & & & & & - \\
\hline
\end{tabular}

GCA models were first fit to the proportion of looks to target on the congruent condition in each individual subject, which provided a baseline measure of spoken word recognition for each child. Next, the nature of each child's congruency effects were estimated by computing difference curves for congruent versus incongruent trials both for looks to target and looks to competitor. The estimated parameters for the intercept, linear, quadratic, and cubic terms were then extracted for each of these curves and correlated with the behavioural measures using a Pearson correlation. 
Results are presented in Table 6. In the baseline condition, no significant correlations were observed between the estimated parameters and the behavioural tasks. The mean proportion, rate, and curvature of fixation patterns to the target in the congruent condition were not related to performance on any behavioural measures. This suggests that under normal constraints spoken word recognition did not differ based on reading, language, or mathematics proficiency.

Any correlation of behavioural measures to the model parameters for difference curves suggests that the magnitude of congruency effects varies based on the behavioural measure of interest. Here, for the target difference curves, a positive correlation was observed between the intercept term and sentence recall measure, in which the mean difference in the proportion of looks between conditions increased with increasing sentence recall scores. For the competitor difference curves, the intercept term estimates were negatively correlated with performance on the TOWRE Sight Word subtest and the colour RAN task. Because difference curves were constructed by subtracting the incongruent condition from the congruent condition, the negative correlation indicates that the mean magnitude of the difference between the two conditions was more negative, suggesting that higher Sight Word and colour RAN performance are related to increased congruency effects. The competitor difference curve's intercept estimates were also positively correlated with performance on the letter and sound knowledge task, and its linear estimates were positively correlated with letter and sound knowledge scores. This pattern suggests that as letter and sound knowledge scores increase, the mean difference in the proportion of looks between conditions becomes larger, or less negative, and the slope in difference curves also becomes larger, or less negative. That is, increased letter and sound knowledge scores were related to smaller congruency effects. 
Because the TOWRE subtests were also completed by adult participants, the correlation between these tasks and estimated parameters was also examined within the entire sample. The Sight Word Efficiency subtest of the TOWRE was negatively correlated with the intercept term of the competitor difference curves $(r=-0.3687, p<.01)$. These results replicated the correlation observed in the younger group of the sample. In both children and adults, higher TOWRE Sight Word scores were associated with more negative mean differences between conditions, representing a larger congruency effect. 
Table 6. Correlation of growth curve parameter estimates with behavioural measures in children.

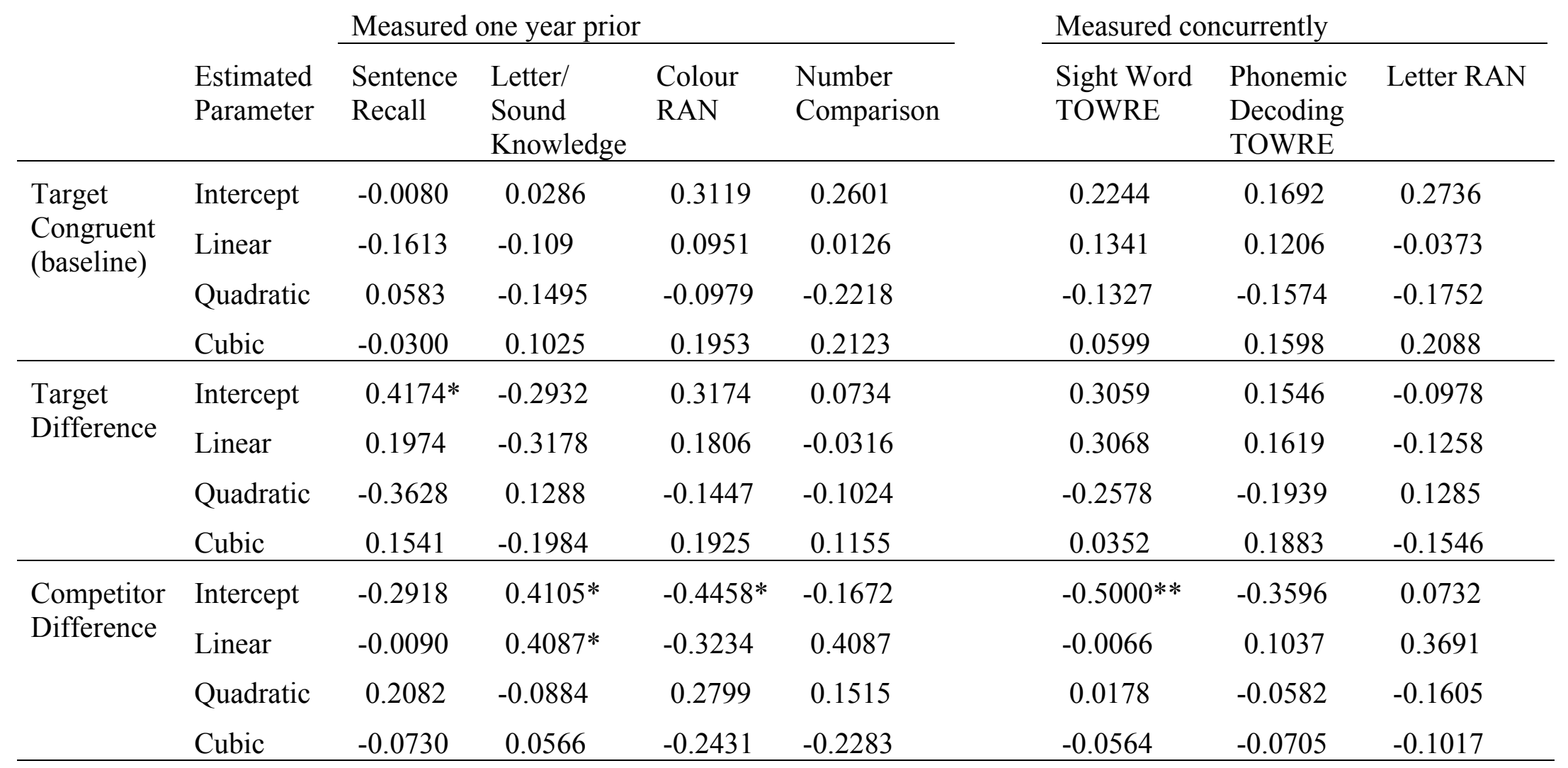

$$
\begin{aligned}
& * p<.05 \\
& * * p<.01
\end{aligned}
$$




\section{Discussion}

The present study compared sensitivity to coarticulatory cues in children and adults using eyetracking. School-aged children and adults completed a picture-word matching task while listening to spoken words containing congruent and incongruent coarticulatory information. Analysis of the button press responses during the eyetracking task indicated that children and adults were able to accurately match the word to the target picture in both the congruent and the incongruent conditions. This suggests that children and adults were able to accurately recognize words even in the presence of incongruent coarticulatory information. Reaction times in children were significantly slower than in adults, consistent with evidence indicating that speed of processing on a variety of timed tasks, including picture-word naming, recognition, and reading tasks, increases from childhood to adulthood (Kail, 1991). Of greater interest were potential differences in RTs for congruent versus incongruent trials. The finding that children responded significantly faster on incongruent trials compared congruent trials was unexpected. Interpreted alone, the button press response time on congruent trials suggests that spoken word recognition was slowed in the congruent condition. However, on the eyetracking task, maximum proportions of looks were reached at similar time points in the congruent and incongruent condition. This suggests that children's eye movements reflected similar word recognition latencies even in the presence of incongruent coarticulatory information.

Growth curve analysis (GCA) of the proportion of looks to each picture reflected the effects of congruency in both adults and children. In the adult group, GCAs of looks demonstrated that the congruent and incongruent conditions differed in both their 
estimated parameters and model fit. This effect was present in the patterns of looks to the target picture, as well as to the competitor. When presented with incongruent coarticulatory information, adults fixated more slowly on the target picture, and more quickly and to a greater degree on the competitor picture. Similar analyses of looks in children revealed differences between the two coarticulatory conditions. Significant differences in parameter estimates demonstrated that children fixated at a slower rate to the target picture on incongruent trials. Additionally, children fixated more quickly and to a greater degree to the competitor picture on incongruent trials. This pattern of results indicates that both children and adults are sensitive to incongruent coarticulatory information in speech, and suggests that phonetic information guides eye movements during spoken word recognition. It is important to note that although congruency effects were observed, both children and adults performed highly accurately on the picture-word matching task. That is, although incongruent phonetic information may have slowed lexical access, both groups were still able to accurately recognize the target word. This is in line with previous research suggesting that in adults, target words are still ultimately recognized in the presence of incongruent coarticulatory information (Dahan, Magnuson, Tanenhaus, \& Hogan, 2001).

Analyses comparing children to adults yielded significant differences in the intercept, linear, and quadratic parameters for looks to the target picture, but no significant differences in looks to the competitor picture. With respect to the pattern of looks to the target picture, this translates to a more negative slope and a broader maximum peak in the difference curve. A more negatively sloped difference curve represents a more quickly decreasing difference between the congruent and incongruent 
conditions. Although this finding suggests that the congruency effect in children decreased more quickly, the observed data suggests that the negative slope is driven by the tails of the data rather than the initial response to coarticulatory cues in the word onset. The broader maximum peak indicates that the difference between conditions is largest for a longer period of time, suggesting that children's eye movements to the target picture are slowed for longer than adults' eye movements.

Overall, these results suggest that a slightly larger congruency effect was present in children, in which there was more competition between the competitor and target picture when an incongruent stimulus was present. This may indicate that coarticulatory cues are more important for spoken word recognition in children than in adults. Children may be overly sensitive to coarticulatory cues, leading to an increased response to incongruent information. The theoretical implications of this hypothesis are discussed in detail below.

Analyses were also conducted to examine whether sensitivity to coarticulatory information differed among phonetic contrasts, and whether this varied in children versus adults. Different articulatory features of phonemes allow coarticulation to be carried to varying degrees. The current study used stimuli beginning with $/ \mathrm{f} /, / \mathrm{h} /, / \mathrm{m} /$, with incongruent coarticulatory cues artificially inserted in the word initial consonant. In comparing coarticulatory sensitivity across phonemes, larger congruency effects were observed in $/ \mathrm{h} /$ and $/ \mathrm{m} /$ compared to $/ \mathrm{f} /$ in both groups. When the manner of articulation of these consonants is considered, this finding is unsurprising. The phoneme $/ \mathrm{h} /$, a glottal glide, is articulated with no obstruction of airflow, providing ample opportunity for the articulators to coarticulate upcoming vowels. The phoneme $/ \mathrm{m} /$ is a nasal bilabial 
consonant, involving airflow through the nose rather than the mouth. The tongue has no distinctive function in the articulation of $/ \mathrm{m} /$ in English, and speakers can use the tongue to anticipate the upcoming vowel's articulation ( $\mathrm{Su}, \mathrm{Li}, \& \mathrm{Fu}, 1974)$. Finally, the consonant /f/ is a labiodental fricative produced by partially blocking airflow. The air turbulence required to produce a fricative is thought to constrain the tongue's position (Shadle, 1985), reducing the opportunity for anticipatory coarticulation. These articulatory features allow coarticulatory information to be carried more in $/ \mathrm{h} /$ and $/ \mathrm{m} /$. Incongruent stimuli beginning with the consonants $/ \mathrm{h} /$ and $/ \mathrm{m} /$ are therefore likely to contain more incongruent information. The increased congruency effect observed in children and adults' eye movements for stimuli beginning with $/ \mathrm{h} /$ and $/ \mathrm{m} /$ reflected this hypothesis.

Next, the interaction of group and phoneme contrast was examined. Although the target difference curves did not demonstrate any significant interaction with group, an interaction of group and phoneme contrast was observed in the competitor difference curves. Children and adults demonstrated similar responses to coarticulatory incongruity for the consonants $/ \mathrm{f} /$ and $/ \mathrm{m} /$. However, the congruency effect observed for the phoneme /h/ was significantly larger in children than in adults. Because the articulation of $/ \mathrm{h} /$ allows the consonant to carry large amounts of coarticulatory information, the incongruity in this phoneme is likely more salient compared to the other stimuli. It is possible that children are better able to detect more salient coarticulatory information, leading to a larger response to salient incongruency in children.

Finally, children's curve parameters were correlated with reading, language, and cognitive measures to examine whether spoken word recognition related to performance 
on these tasks. Looks to the target in the congruent condition, representing a baseline measure of spoken word recognition, were not correlated with any behavioural measures. This finding suggests that the rate of spoken word recognition, as measured by eye movements, is not related to reading, language, or mathematics proficiency.

Difference curve parameters were correlated with behavioural performance to examine whether congruency effects were related to measures of reading, language, or mathematics. The mathematics measure, a number comparison task, was not expected to relate to spoken word recognition and was included as a measure of general learning proficiency. As expected, performance on the number comparison task was not correlated with difference curve parameters for the target and competitor picture. This suggests that mathematics performance, and perhaps general learning, are not related to sensitivity to incongruent coarticulatory information.

The positive correlation of the sentence recall measure with the intercept term of the target difference curves suggests that the average magnitude of the difference effect is related to sentence recall performance. More specifically, children who were able to better recall sentences demonstrated larger congruency effects. As the sentence recall task is a predictor of oral language proficiency, this suggests that children with better oral language skills are more sensitive to coarticulatory information. This finding is consistent with research relating perception of phonetic features to oral language proficiency in the general population (Molfese \& Molfese, 1997; Tsao, Liu, \& Kuhl, 2004) and in SLI (Ziegler et al., 2005; Archibald \& Joanisse, 2012).

A number of measures of reading proficiency were correlated with parameters of the competitor difference curves. Here, because the competitor differences curves are 
negative-going curves, negative correlations represent the association of increased behavioural scores with larger congruency effects. Performance on the colour RAN tasks ten months prior to eyetracking, as well as performance on the TOWRE Sight Word subtest during the eyetracking session, were negatively correlated with the intercept terms of the competitor difference curves. The colour RAN task is a predictor of reading accuracy and fluency, suggesting that early naming fluency and accuracy is related to later congruency effects. Increased TOWRE Sight Word performance, a measure of reading fluency and accuracy, was also associated with increased congruency effects. This pattern of results suggests that increased fluency and accuracy in reading are related to increased sensitivity to phonetic detail in speech. However, performance on the letter and sound knowledge task was positively correlated with the intercept and linear terms of the competitor difference curve. A positive correlation of the intercept and linear terms represents a smaller, or less negative, difference between congruency conditions and a slower rate of increase in this difference. In contrast with the results from the colour RAN and TOWRE tasks, this finding suggests that higher reading proficiency is related to decreased sensitivity to phonetic detail in speech. While these results are difficult to reconcile, examination of the correlations between each test suggests that the letter knowledge task may not have been a sensitive measure of later reading fluency and accuracy. The letter and sound knowledge task was not significantly correlated with later performance on the TOWRE Sight Word subtest and the TOWRE Phonemic Decoding subtest. Colour RAN was positively correlated to TOWRE Sight Word performance and its correlation with the TOWRE Phonemic Decoding measure neared significance. These 
findings suggest that while the colour RAN task predicted later reading performance, the letter and sound knowledge task was not a reliable predictor of reading proficiency.

The negative correlation between adults' TOWRE Sight Word performance and the intercept term of the competitor difference curve replicated the relationship observed in children. These findings suggest that in both children and adults, increased reading proficiency is associated with increased sensitivity to coarticulatory cues.

\section{Theoretical Implications}

Overall, the results of the present study indicate that both adults and children are sensitive to coarticulatory information during spoken word recognition. In line with previous studies of adults, this suggests that sublexical phonetic information is abstracted during spoken word recognition. Although earlier models of spoken word recognition posited that auditory input was broken into phoneme units and the lexicon was searched without abstraction of phonetic detail (Forster, 1976), current models suggest that acoustic properties of speech are mapped onto phonetic features during spoken word recognition. The TRACE model of spoken word recognition (McClelland \& Elman, 1986) is a connectionist model consisting of three layers of interconnected units: a feature layer representing the acoustic properties of the speech input, a phoneme layer, and a word layer. TRACE simulates word recognition by abstracting a numerical pattern of acoustic-phonetic properties in a word, mapping them onto phoneme units to activate individual phonemes, and then in turn activating a single lexical unit. TRACE is dynamic and interactive, meaning that all units compete in parallel for selection and both bottomup and top-down information influence activation. Empirical coarticulatory effects have been simulated in TRACE. For example, Dahan et al. (2001) simulated their spoken word 
recognition task using TRACE, and found that the simulation replicated the observed patterns of fixations in the presence of incongruent coarticulatory cues. These findings, in conjunction with the results of the present study, suggest that both adults and children abstract phonetic features of speech in prelexical stages of spoken word recognition.

The differences in congruency effects in children and adults may represent differences in sensitivity to phonetic detail in spoken language. Several researchers have argued that children's representations become more segmented or phonetically detailed over time (Walley, 1993; Elbro, 1996), or that children may learn to assign different perceptual weights to acoustic detail over time (Nittrouer \& Miller, 1997). These weights are thought to change over time with increased experience with speech, as children learn the phonetic informativeness of different acoustic properties. Under this account, the slightly larger congruency effect observed in children may be a result of a high perceptual weighting to coarticulatory cues. Children would therefore be overly sensitive to coarticulatory incongruency, resulting in a larger difference between the congruent and incongruent conditions in the present study. Adults, with increased experience with variability in speech, may have reduced the perceptual weighting to coarticulatory information to cope with this variability. The interaction of the phoneme variable and group could also be explained under this framework. The articulation of the phoneme $/ \mathrm{h} /$ allows for more anticipatory coarticulatory, and children's increased sensitivity to coarticulatory information could therefore result in a larger response to more salient coarticulatory cues.

Under the framework of the TRACE model, this change in perceptual weighting could be represented by changes in bidirectional weights between the feature units and 
phoneme units. To further investigate this hypothesis, the current study was simulated in jTRACE (Strauss, Harris, \& Magnusson, 2007), a reimplementation of the TRACE model. Some articulatory features of model input were altered to examine the subsequent competition between lexical units during word recognition. Specifically, the articulatory features of the initial consonant in "sap" were manipulated to partially reflect the articulatory features of the initial consonant of "suit" to create an incongruent stimulus "su" $a p$ ". As shown in the left panels of Figures 6 and 7, simulation of word recognition of this incongruent stimulus mirrored the congruency effect observed in children and adults, in which activation of "sap" was slightly slowed and activation of "suit" was increased. The simulation was then repeated while manipulating the feature-phoneme, to represent changes in weights over time. Increasing the feature-phoneme weights led to an increased congruency effect (see right panels of Figures 6 and 7). In other words, the congruency pattern observed in children was simulated by increasing the weights between the feature and phoneme units. This simulation suggests that in adults, feature-phoneme weights may be decreased to reduce the importance of coarticulatory information during spoken word recognition. This weighting reduction may occur over time as adults gain experience with variability in acoustic cues of individual phonemes. Importantly, the presence of a congruency effect in adults suggests that weightings are not reduced enough to completely abolish sensitivity to coarticulation, allowing adults to still use the systematicity of coarticulation during speech perception but reducing the load of the variability experienced ubiquitously in spoken language.

The jTRACE simulation in the current study was quite simplistic, and more indepth simulation of the present study in jTRACE could help further understanding of the 
relationship between lexical development and coarticulatory sensitivity. Specifically, a more methodical simulation of various inputs and manipulation of bottom-up and topdown weights could shed additional light on the role of perceptual weights during spoken word recognition to separate the two possible explanations of the results of the current study. Additional simulation of various phonetic contrasts could examine whether different articulatory properties yield different congruency effects in jTRACE, to replicate the pattern observed in children in the present study. Additionally, a longitudinal study of phonetic sensitivity in children of different ages could contribute to an understanding of the developmental changes in lexical representation and spoken word recognition. The current body of research on phonetic sensitivity focuses on sensitivity to native and non-native phonetic contrasts in infants, and extension of this research to early and later years of language development could further explore changes in use of phonetic detail during spoken word recognition. 

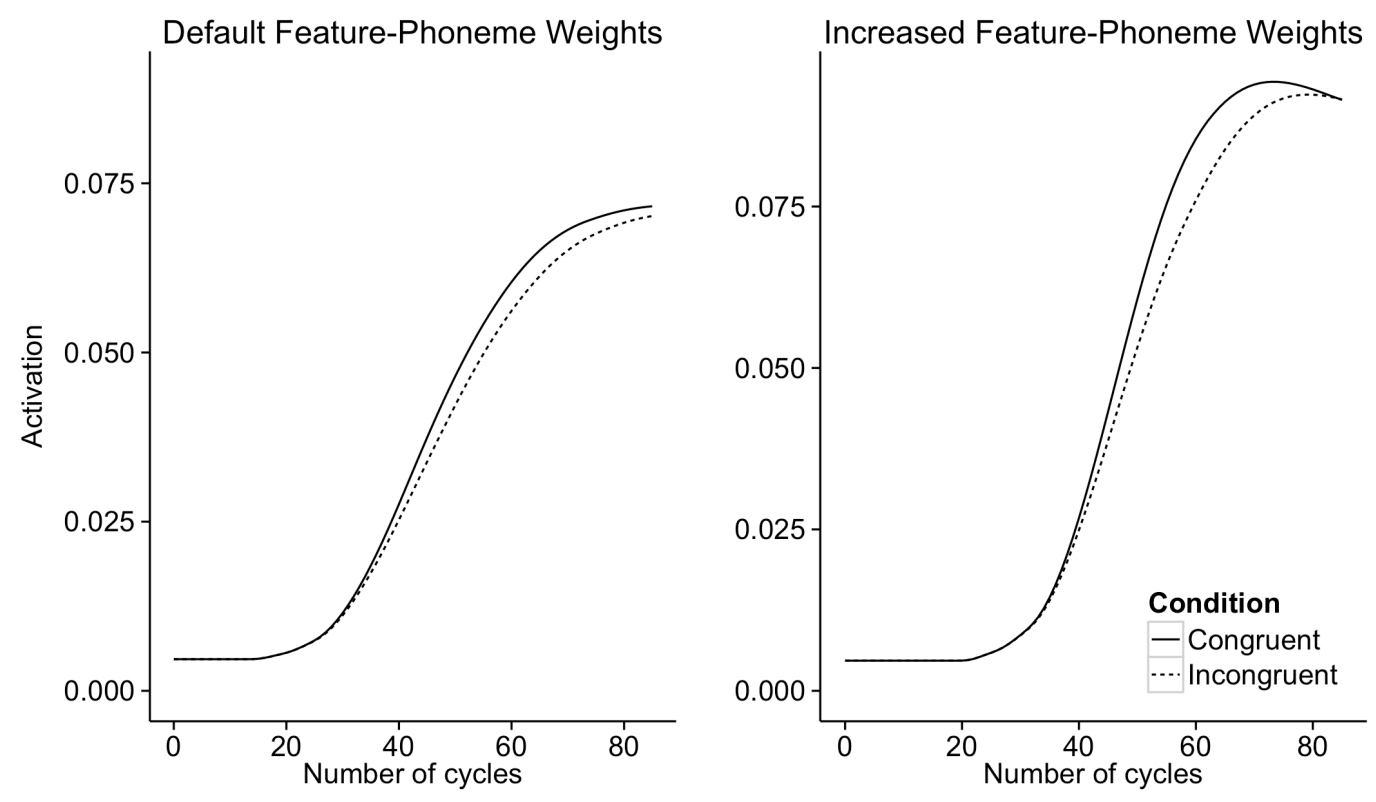

Figure 6. jTRACE simulation of target word activation. The simulation was conducted with the feature-phoneme weights set to their default, 0.02 , and with the feature-phoneme weights increased to 0.04 .
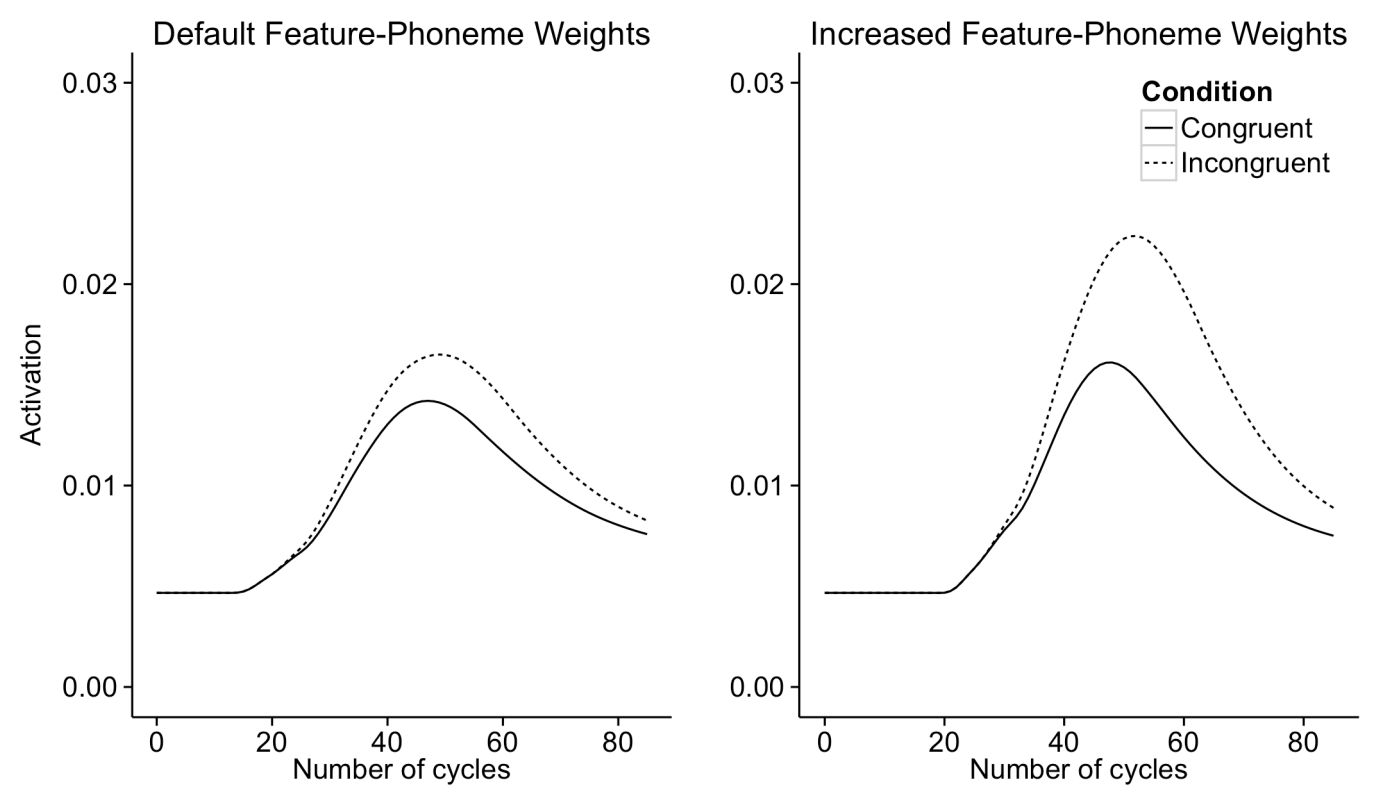

Figure 7. jTRACE simulation of competitor word activation. The simulation was conducted with the feature-phoneme weights set to their default, 0.02 , and with the feature-phoneme weights increased to 0.04 . 
The present study also demonstrated that some changes in sensitivity to phonetic detail may be related to reading and language skills. The relationship of congruency effects to behavioural measures suggests that the phonological skills measured by coarticulatory responses relate to oral language and reading proficiency. Under the framework described above, children who struggle with oral language or reading may have difficulty assigning perceptual weights to phonetic information. This is consistent with accounts of speech perception deficits in SLI (Archibald \& Gathercole, 2007; Archibald \& Joanisse, 2012) and suggests that in the general population, individual differences in oral language proficiency are related to coarticulatory sensitivity and, more broadly, use of phonetic detail during spoken word recognition. Findings of speech perception deficits in dyslexia have yielded mixed results (i.e. see Bruno et al., 2007; Griffiths \& Snowling, 2001), but studies that exclude dyslexic children who also have broader language impairments suggest that speech perception deficits are not present in children who only have dyslexia (Joanisse, Manis, Keating, \& Seidenberg, 2000). Here, the sentence recall measure was positively correlated with the TOWRE Sight Word and Phonemic Decoding subtests, suggesting that reading proficiency and language proficiency were related in our sample. Our findings demonstrate that reading and language proficiency are both related to sensitivity to phonetic detail during spoken word recognition, but it remains unclear whether each skill is related independently to coarticulatory sensitivity. Further investigation of this relationship is needed to draw conclusions about how coarticulatory sensitivity may be mediated or moderated by language or reading proficiency. 
Although children participating in the present study displayed a broad range of reading and language abilities, the sample of children may have an overrepresentation of children who performed poorly on the reading and language tasks. This may have resulted in a larger correlation of congruency effects to reading and language performance than would be expected in the general population. In addition, use of more than three phoneme contrasts in the eyetracking paradigm could improve the generalizability of the findings to other phonemes and to speech in general. Future research using a variety of phoneme contrasts could extend the findings of the present study to examine whether the increased congruency response to $/ \mathrm{h} /$ observed in children also extends to other highly coarticulated phonemes.

\section{Conclusions}

The present study aimed to examine coarticulatory cue responses during spoken word recognition in school-aged children and adults. Children and adults completed a picture-word task containing congruent and incongruent coarticulatory cues, while their eye movements to both pictures were measured. Behavioural predictors and measures or reading and language proficiency were also administered in children to examine whether early reading and language skill related to coarticulatory sensitivity.

Overall, the results suggest that both adults and children are sensitive to coarticulatory information during spoken word recognition, but that children may be slightly more sensitive to coarticulatory cues. These results extend studies of coarticulatory cue responses in adults to a school-aged population, to shed light on developmental differences in the use of subtle acoustic information during spoken word recognition. In addition, the results of the current study suggest that individual 
differences in reading and language proficiency are related to sensitivity to coarticulatory cues. 


\section{References}

Allopenna, P. D., Magnuson, J. S., \& Tanenhaus, M. K. (1998). Tracking the time course of spoken word recognition using eye movements: Evidence for continuous mapping models. Journal of Memory and Language, 38(4), 419-439.

Archibald, L. M., \& Gathercole, S. E. (2007). Nonword repetition in specific language impairment: More than a phonological short-term memory deficit. Psychonomic Bulletin \& Review, 14(5), 919-924.

Archibald, L. M., Gathercole, S. E., \& Joanisse, M. F. (2009). Multisyllabic nonwords: More than a string of syllables. The Journal of the Acoustical Society of America, 125(3), 1712-1722.

Archibald, L. M., \& Joanisse, M. F. (2009). On the sensitivity and specificity of nonword repetition and sentence recall to language and memory impairments in children. Journal of Speech, Language, and Hearing Research, 52(4), 899-914.

Archibald, L., \& Joanisse, M. F. (2011). Electrophysiological responses to coarticulatory and word level miscues. Journal of Experimental Psychology: Human Perception and Performance, 37(4), 1275.

Archibald, L. M., \& Joanisse, M. F. (2012). Atypical neural responses to phonological detail in children with developmental language impairments. Developmental Cognitive Neuroscience, 2(1), 139-151.

Bladon, R. A. W., \& Al-Bamerni, A. (1976). Coarticulation Resistance in English /1/. Journal of Phonetics, 4(2), 137-150. 
Blumstein, S. E., \& Stevens, K. N. (1980). Perceptual invariance and onset spectra for stop consonants in different vowel environments. The Journal of the Acoustical Society of America, 67(2), 648-662.

Bond, G. L., \& Dykstra, R. (1967). The cooperative research program in first-grade reading instruction. Reading Research Quarterly, 5-142.

Bowers, P. G., \& Wolf, M. (1993). Theoretical links among naming speed, precise timing mechanisms and orthographic skill in dyslexia. Reading and Writing, 5(1), 69-85.

Bruno, J. L., Manis, F. R., Keating, P., Sperling, A. J., Nakamoto, J., \& Seidenberg, M. S. (2007). Auditory word identification in dyslexic and normally achieving readers. Journal of Experimental Child Psychology, 97(3), 183-204.

Dahan, D., Magnuson, J. S., Tanenhaus, M. K., \& Hogan, E. M. (2001). Subcategorical mismatches and the time course of lexical access: Evidence for lexical competition. Language and Cognitive Processes, 16(5-6), 507-534.

Denckla, M. B., \& Rudel, R. G. (1976). Rapid 'automatized' naming (RAN): Dyslexia differentiated from other learning disabilities. Neuropsychologia, 14(4), 471-479.

Dorman, M. F., Studdert-Kennedy, M., \& Raphael, L. J. (1977). Stop-consonant recognition: Release bursts and formant transitions as functionally equivalent, context-dependent cues. Perception \& Psychophysics, 22(2), 109-122.

Elbro, C. (1996). Early linguistic abilities and reading development: A review and a hypothesis. Reading and Writing, 8(6), 453-485.

Forster, K. I. (1976). Accessing the mental lexicon. New Approaches to Language Mechanisms, 30, 231-256. 
Garlock, V. M., Walley, A. C., \& Metsala, J. L. (2001). Age-of-acquisition, word frequency, and neighborhood density effects on spoken word recognition by children and adults. Journal of Memory and Language, 45(3), 468-492.

Griffiths, Y. M., \& Snowling, M. J. (2001). Auditory word identification and phonological skills in dyslexic and average readers. Applied Psycholinguistics,22(03), 419-439.

Hurtado, N., Marchman, V. A., \& Fernald, A. (2007). Spoken word recognition by Latino children learning Spanish as their first language. Journal of Child Language, 34(02), 227-249.

Joanisse, M. F., Manis, F. R., Keating, P., \& Seidenberg, M. S. (2000). Language deficits in dyslexic children: Speech perception, phonology, and morphology. Journal of Experimental Child Psychology, 77(1), 30-60.

Kail, R. (1991). Developmental change in speed of processing during childhood and adolescence. Psychological Bulletin, 109(3), 490.

LaRiviere, C., Winitz, H., \& Herriman, E. (1975a). The distribution of perceptual cues in English prevocalic fricatives. Journal of Speech, Language, and Hearing Research, 18(4), 613-622.

LaRiviere, C., Winitz, H., \& Herriman, E. (1975b). Vocalic transitions in the perception of voiceless initial stops. The Journal of the Acoustical Society of America, 57(2), 470-475.

Liberman, A. M., Cooper, F. S., Shankweiler, D. P., \& Studdert-Kennedy, M. (1967). Perception of the speech code. Psychological Review, 74(6), 431. 
Manis, F. R., McBride-Chang, C., Seidenberg, M. S., Keating, P., Doi, L. M., Munson, B., \& Petersen, A. (1997). Are speech perception deficits associated with developmental dyslexia?. Journal of Experimental Child Psychology, 66(2), 211235.

Marslen-Wilson, W., \& Warren, P. (1994). Levels of perceptual representation and process in lexical access: words, phonemes, and features. Psychological Review, 101(4), 653.

McClelland, J. L., \& Elman, J. L. (1986). The TRACE model of speech perception. Cognitive Psychology, 18(1), 1-86.

McMurray, B., Tanenhaus, M. K., \& Aslin, R. N. (2002). Gradient effects of withincategory phonetic variation on lexical access. Cognition, 86(2), B33-B42.

McQueen, J. M., Norris, D., \& Cutler, A. (1999). Lexical influence in phonetic decision making: Evidence from subcategorical mismatches. Journal of Experimental Psychology: Human Perception and Performance, 25(5), 1363.

Mirman, D. (2014). Growth curve analysis and visualization using R. CRC Press.

Mirman, D., Dixon, J. A., \& Magnuson, J. S. (2008). Statistical and computational models of the visual world paradigm: Growth curves and individual differences. Journal of Memory and Language, 59(4), 475-494.

Mitterer, H., \& Blomert, L. (2003). Coping with phonological assimilation in speech perception: Evidence for early compensation. Perception \& Psychophysics, 65(6), 956-969. 
Molfese, D. L., \& Molfese, V. J. (1997). Discrimination of language skills at five years of age using event-related potentials recorded at birth. Developmental Neuropsychology, 13(2), 135-156.

Nittrouer, S., \& Miller, M. E. (1997). Predicting developmental shifts in perceptual weighting schemes. The Journal of the Acoustical Society of America, 101(4), 22532266.

Norris, D., McQueen, J. M., \& Cutler, A. (2000). Merging information in speech recognition: Feedback is never necessary. Behavioral and Brain Sciences, 23(03), 299-325.

Nosworthy, N., Bugden, S., Archibald, L., Evans, B., \& Ansari, D. (2013). A two-minute paper-and-pencil test of symbolic and nonsymbolic numerical magnitude processing explains variability in primary school children's arithmetic competence. PloS One, 8(7), e67918.

Scarborough, H. S. (1998). Predicting the future achievement of second graders with reading disabilities: Contributions of phonemic awareness, verbal memory, rapid naming, and IQ. Annals of Dyslexia, 48(1), 115-136.

Shadle, C. H. (1985). The acoustics of fricative consonants. Massachusetts Institute of Technology.

Stevens, K. N., \& House, A. S. (1963). Perturbation of vowel articulations by consonantal context: An acoustical study. Journal of Speech \& Hearing Research.

Strauss, T. J., Harris, H. D., \& Magnuson, J. S. (2007). jTRACE: A reimplementation and extension of the TRACE model of speech perception and spoken word recognition. Behavior Research Methods, 39(1), 19-30. 
Su, L. S., Li, K. P., \& Fu, K. S. (1974). Identification of speakers by use of nasal coarticulation. The Journal of the Acoustical Society of America, 56(6), 1876-1883.

Swingley, D., \& Aslin, R. N. (2000). Spoken word recognition and lexical representation in very young children. Cognition, 76(2), 147-166.

Swingley, D., \& Aslin, R. N. (2002). Lexical neighborhoods and the word-form representations of 14-month-olds. Psychological Science, 13(5), 480-484.

Tanenhaus, M. K., Magnuson, J. S., Dahan, D., \& Chambers, C. (2000). Eye movements and lexical access in spoken-language comprehension: Evaluating a linking hypothesis between fixations and linguistic processing. Journal of Psycholinguistic Research, 29(6), 557-580.

Tanenhaus, M. K., Spivey-Knowlton, M. J., Eberhard, K. M., \& Sedivy, J. C. (1995). Integration of visual and linguistic information in spoken language comprehension. Science, 268(5217), 1632-1634.

Torgesen, J. K., Wagner, R. K., \& Rashotte, C. A. (1999). Test of word reading efficiency (TOWRE). Austin, TX: Pro-Ed.

Tsao, F. M., Liu, H. M., \& Kuhl, P. K. (2004). Speech perception in infancy predicts language development in the second year of life: A longitudinal study. Child development, 1067-1084.

Walley, A. C. (1993). The Role of Vocabulary Development in Children's Spoken Word Recognition and Segmentation Ability. Developmental review, 13(3), 286-350.

Werker, J. F., \& Tees, R. C. (1987). Speech perception in severely disabled and average reading children. Canadian Journal of Psychology/Revue Canadienne de Psychologie, 41(1), 48. 
Ziegler, J. C., Pech-Georgel, C., George, F., Alario, F. X., \& Lorenzi, C. (2005). Deficits in speech perception predict language learning impairment. Proceedings of the National Academy of Sciences of the United States of America, 102(39), 1411014115. 


\section{Appendix A}

Sentence recall task and scoring. Participants listened to the sentences below in headphones and were asked to repeat them aloud.

\begin{tabular}{|l|c|c|c|}
\hline Item & \multicolumn{3}{|c|}{ Circle one } \\
\hline S01. The big football player washed the car with the hose. & 2 & 1 & 0 \\
\hline S02. All of the pictures were coloured by his little sister. & 2 & 1 & 0 \\
\hline $\begin{array}{l}\text { S03. The rose bushes were planted yesterday by the girl } \\
\text { scouts. }\end{array}$ & 2 & 1 & 0 \\
\hline S04. The happy little girl kicked the ball over the fence. & 2 & 1 & 0 \\
\hline S05. His little brother cleaned the dirty dishes and cups. & 2 & 1 & 0 \\
\hline S06. A special cage was made to hold the dangerous animals. & 2 & 1 & 0 \\
\hline $\begin{array}{l}\text { S07. Everybody in my school coloured Easter eggs for the } \\
\text { picnic. }\end{array}$ & 2 & 1 & 0 \\
\hline S08. A new hole was dug for the kid's swimming pool. & 2 & 1 & 0 \\
\hline S09. Only the first graders made a birdhouse for their parents. & 2 & 1 & 0 \\
\hline S10. My little sister's dog caught the ball on the first bounce. & 2 & 1 & 0 \\
\hline S11. The soccer ball was kicked into the school's parking lot. & 2 & 1 & 0 \\
\hline S12. The lion's teeth were cleaned with a giant toothbrush. & 2 & 1 & 0 \\
\hline S13. Some of the kids dug holes in the sand two feet deep. & 2 & 1 & 0 \\
\hline S14. The little white mouse was caught by our neighbour's cat. & 2 & 1 & 0 \\
\hline S15. The second grade students planted coconuts in the garden. & 2 & 1 & 0 \\
\hline S16. The dirty clothes were washed with soap one more time. & 2 & 1 & 0 \\
\hline
\end{tabular}

(2=correct; $1=3$ or fewer errors; $0=4$ or more errors) 


\section{Appendix B}

Letter and sound knowledge task. Participants pointed to each letter on the forms below and were asked to name the sound of the letter aloud. Following completion of sound naming for the upper- and lower-case letters, participants named upper- and lower-case letters. Performance was scored on the following form.

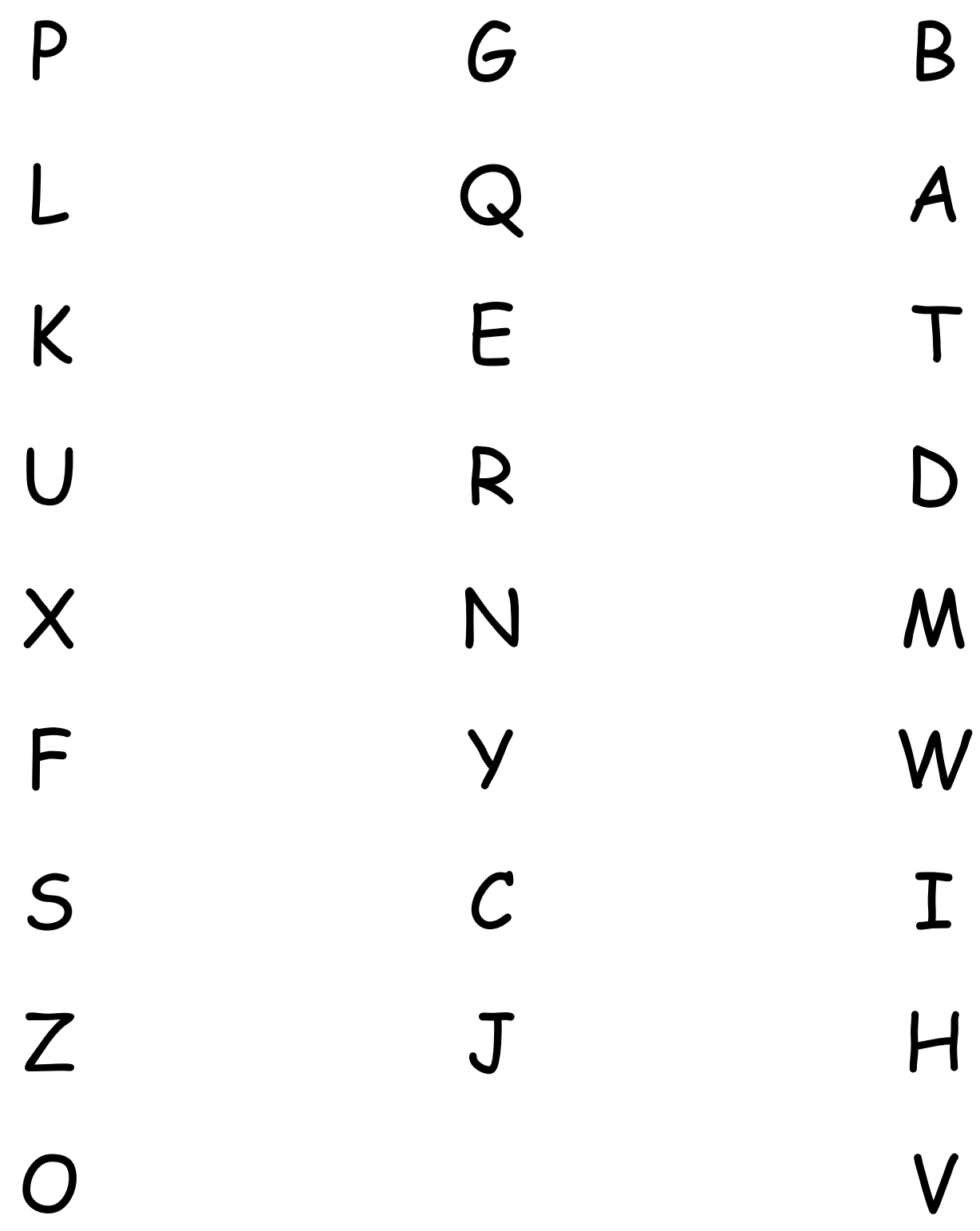




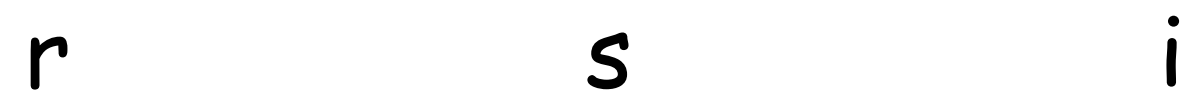

b

V

$x$

m

k

$\dagger$

0

y

d

C

Z

e

W

a

I

9

$f$

h

9

$n$

$p$

j

$u$ 


\begin{tabular}{|c|c|c|c|c|c|}
\hline & \multicolumn{2}{|c|}{ UPPER CASE } & & \multicolumn{2}{|c|}{ LOWER CASE } \\
\hline & Knows sound & Knows name & & Knows sound & Knows name \\
\hline$P$ & & & $r$ & & \\
\hline G & & & $s$ & & \\
\hline B & & & $\mathrm{i}$ & & \\
\hline L & & & $b$ & & \\
\hline$Q$ & & & $v$ & & \\
\hline A & & & $x$ & & \\
\hline $\mathrm{K}$ & & & $\mathrm{m}$ & & \\
\hline$E$ & & & $\mathrm{k}$ & & \\
\hline $\mathrm{T}$ & & & $\mathrm{t}$ & & \\
\hline U & & & 0 & & \\
\hline$R$ & & & 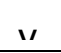 & & \\
\hline D & & & $d$ & & \\
\hline$x$ & & & C & & \\
\hline $\mathrm{N}$ & & & $z$ & & \\
\hline $\mathrm{M}$ & & & e & & \\
\hline$F$ & & & w & & \\
\hline$Y$ & & & $a$ & & \\
\hline W & & & 1 & & \\
\hline$S$ & & & $\mathrm{~g}$ & & \\
\hline C & & & $f$ & & \\
\hline I & & & $\mathrm{h}$ & & \\
\hline Z & & & $q$ & & \\
\hline $\mathrm{J}$ & & & $\mathrm{n}$ & & \\
\hline $\mathrm{H}$ & & & $p$ & & \\
\hline 0 & & & $\mathrm{j}$ & & \\
\hline V & & & $\mathrm{u}$ & & \\
\hline
\end{tabular}

Place a checkmark for all correct responses and a dash (-) for errors. 


\section{Appendix C}

Colour RAN task. Participants were first shown the practice sheet and asked to name the four colours. Participants were then shown the following form and asked to name each colour as quickly and accurately as possible. The scoring sheet follows. 

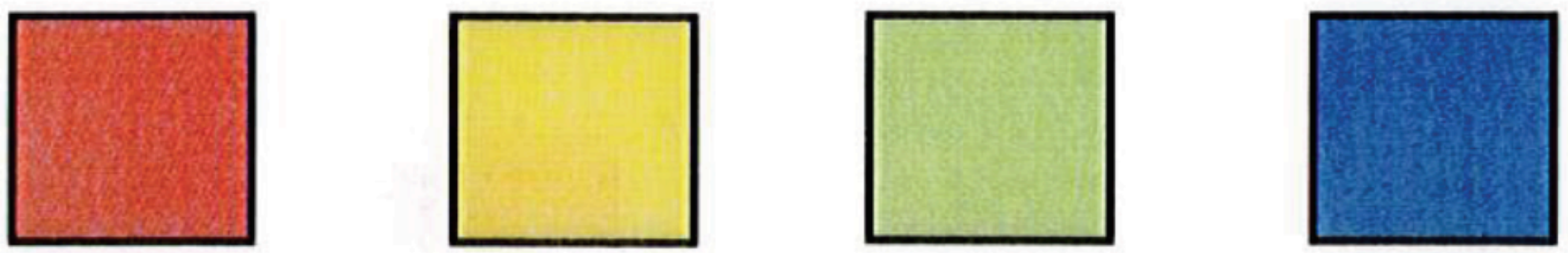

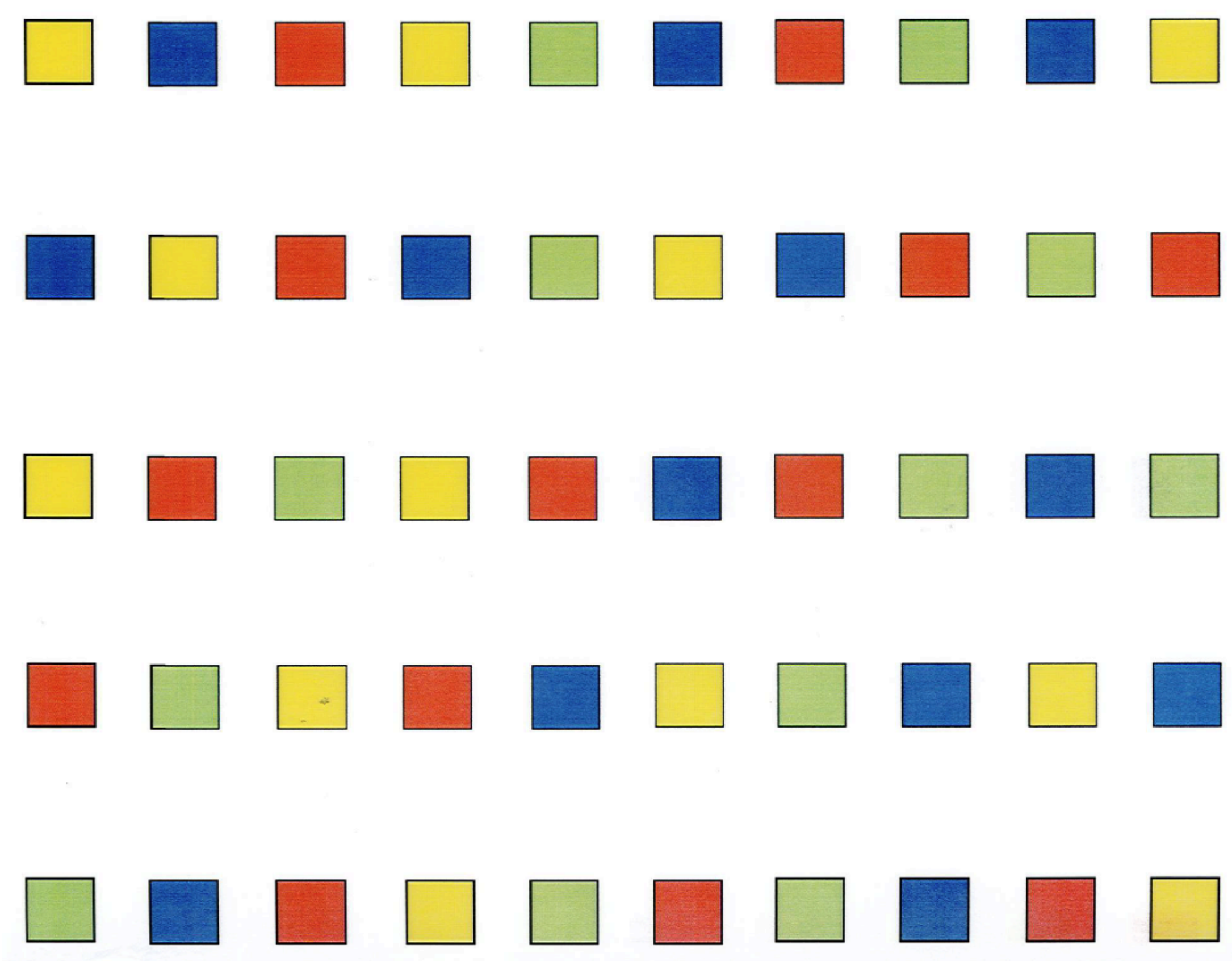


\begin{tabular}{|c|c|c|c|c|c|c|c|c|c|}
\hline Yellow & Red & Blue & Green & Red & Green & Yellow & Red & Blue & Green \\
\hline Blue & Yellow & Blue & Green & Yellow & Blue & Red & Yellow & Green & Red \\
\hline Green & Blue & Green & Red & Blue & Red & Yellow & Green & Red & Yellow \\
\hline Red & Green & Red & Blue & Yellow & Green & Blue & Red & Yellow & Blue \\
\hline Yellow & Blue & Green & Red & Blue & Green & Yellow & Red & Blue & Yellow \\
& & & & & & & & & \\
\hline
\end{tabular}

Place a slash (/) on any incorrectly named colours.

Total: 150

Time (seconds): 


\section{Appendix D}

Letter RAN task. Participants were first shown the practice sheet and asked to name the four letters Participants were then shown the following form and asked to name each letter as quickly and accurately as possible. The scoring sheet follows. 
k r m g 
k $\quad r \quad m \quad g \quad m \quad r \quad k \quad g \quad r \quad k$

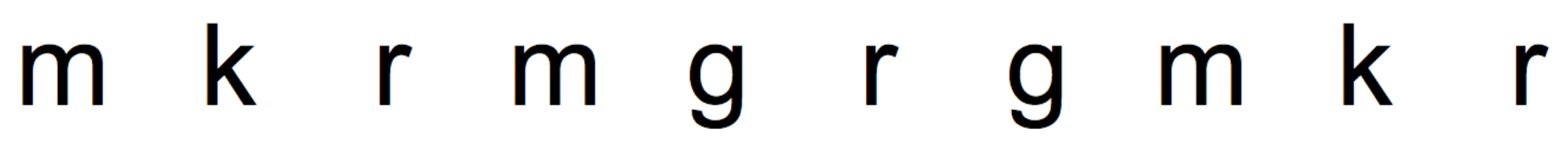

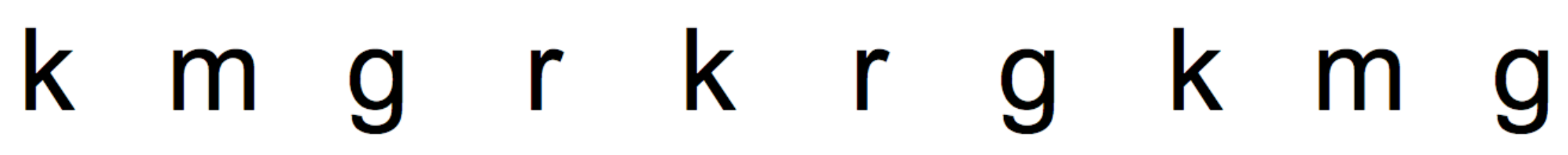

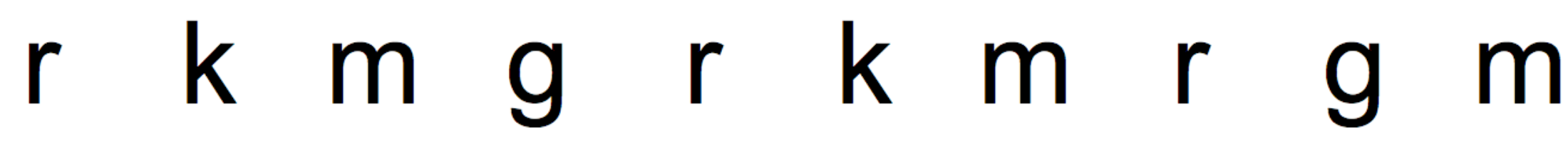

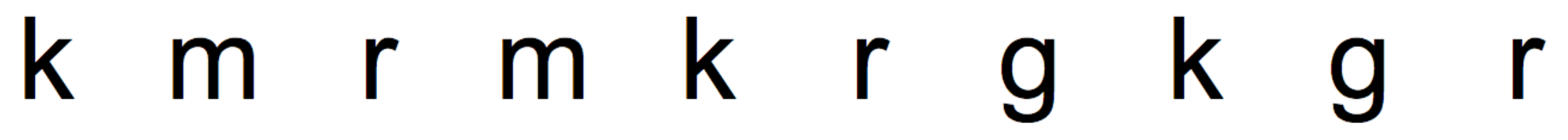




\section{Appendix E}

\section{Research Ethics Board approval for eyetracking studies in adults and children.}
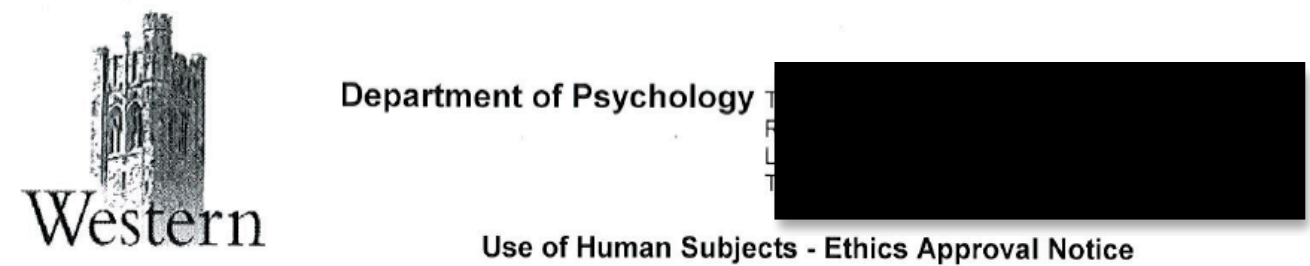

\begin{tabular}{|c|c|c|c|}
\hline Review Number & 120916 & Approval Date & 120919 \\
\hline Principal Investigator & Marc Joanisse/Danielle LaPorte & End Date & 130830 \\
\hline Protocol Title & \multicolumn{3}{|c|}{ Predicting reading ability with spoken language understanding in adults } \\
\hline Sponsor & $\mathbf{n} / \mathbf{a}$ & & \\
\hline
\end{tabular}

This is to notify you that The University of Western Ontario Department of Psychology Research Ethics Board (PREB) has granted expedited ethics approval to the above named research study on the date noted above.

The PREB is a sub-REB of The University of Western Ontario's Research Ethics Board for Non-Medical Research Involving Human Subjects (NMREB) which is organized and operates according to the Tri-Council Policy Statement and the applicable laws and regulations of Ontario. (See Office of Research Ethics web site: http://www.uwo.ca/research/ethics/)

This approval shall remain valid until end date noted above assuming timely and acceptable responses to the University's periodic requests for surveillance and monitoring information.

During the course of the research, no deviations from, or changes to, the protocol or consent form may be initiated without prior written approval from the PREB except when necessary to eliminate immediate hazards to the subject or when the change(s) involve only logistical or administrative aspects of the study (e.g. change of research assistant, telephone number etc). Subjects must receive a copy of the information/consent documentation.

Investigators must promptly also report to the PREB:

a) changes increasing the risk to the participant(s) and/or affecting significantly the conduct of the study;

b) all adverse and unexpected experiences or events that are both serious and unexpected;

c) new information that may adversely affect the safety of the subjects or the conduct of the study.

If these changes/adverse events require a change to the information/consent documentation, and/or recruitment advertisement, the newly revised information/consent documentation, and/or advertisement, must be submitted to the PREB for approval.

Members of the PREB who are named as investigators in research studies, or declare a conflict of interest, do not participate in discussion related to, nor vote on, such studies when they are presented to the PREB.

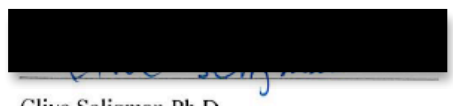

Clive Seligman Ph.D

Chair, Psychology Expedited Research Ethics Board (PREB)

The other members of the 2012-2013 PREB are: Mike Atkinson (Introductory Psychology Coordinator), Rick Goffin, Riley Hinson Albert Katz (Department Chair), Steve Lupker, and TBA (Graduate Student Representative) 

NMREB Amendment Approval Notice

Principal Investigator: Prof. Marc Joanisse

Department \& Institution: Social SciencelPsychology, Western University

VMREB File Number: 104238

Study Title: Predicting reading abiiity with spoken language understanding in adults Sponsor:

NMRE,B Revision Approval Date: August 01, 2014

NuREB Expiry Date: August 30, 2015

Dociments Approved and/or Received for Information:

\begin{tabular}{|c|c|c|}
\hline Document Name & Comments & $\begin{array}{l}\text { Version } \\
\text { Date }\end{array}$ \\
\hline $\begin{array}{l}\text { Revised Study End } \\
\text { Date }\end{array}$ & Study extension from 30Aug2014 to 30Aug2015 & $20|4 / 08 / 0|$ \\
\hline $\begin{array}{l}\text { Western University } \\
\text { ['rotocol }\end{array}$ & 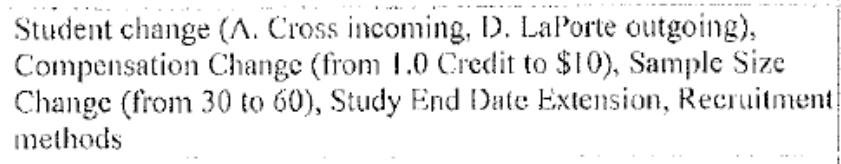 & $2014 / 06 / 17$ \\
\hline Recruitment Items & & $2014 / 08 / 01$ \\
\hline $\begin{array}{l}\text { Revised Letter of } \\
\text { Information \& } \\
\text { Consent }\end{array}$ & & $2014 / 08 / 01$ \\
\hline
\end{tabular}

The Western University Non-ivedical Science Research Ethies Board (NMIREB) has reviewed and approved the amendinent fo the above named study, as of the NMREB Amendment Approval Date noted above

NMRER approval for this study remains valid until the NMREB Expiry Date noted above, conditional to timely submission and acceptance of HSREB Contintuing Ethics Review.

The Westem University NMREB operates in compliance with the Tri-Council Poljey Statement Ethical Conduct for Reseasch lnvolving Humans (TCPS2), the Ontatio Personal Health [nformation Protection Act (PfIIPA, 2004), and the ipplicable laws and regulations of Ontario.

Members of the NMREB who are maned as Investigators in research studies do not participate in discussions related to. ner vote on sticl studies when they are presented to the REB.

The NMREB is registered with the U.S. Departmen of Health \& IItman Scrvices under the IRB registration number IRB 0000094 I.

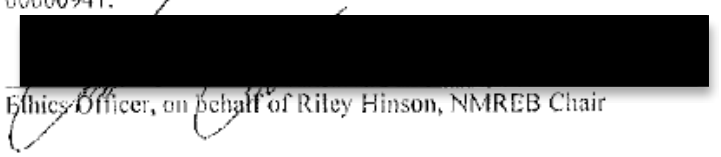

Ethics Officer to Contact for Further Information

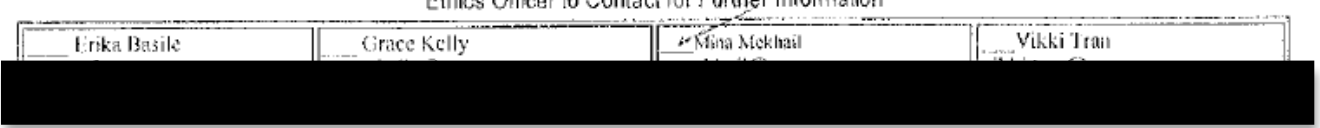

This is an official document. Plase reain the original in your files.

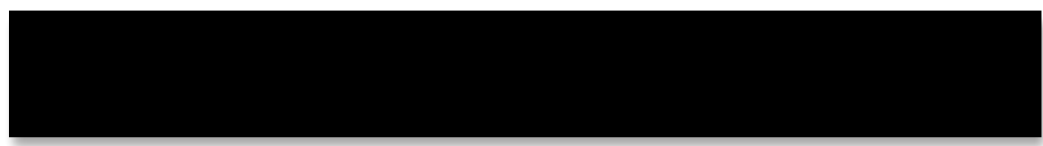




\section{Western 8 \\ se of Human Participants - Ethics Approval Notice}

Research Ethics

\begin{tabular}{|c|c|c|}
\hline \multicolumn{3}{|c|}{$\begin{array}{l}\text { Principal Investigator: Dr. Marc Joanisse } \\
\text { File Number:103169 } \\
\text { Review Level: Full Board } \\
\text { Approved Local Adult Participants: } 0 \\
\text { Approved Local Minor Participants: } 60 \\
\text { Protocol Title: Predicting reading ability with spoken language understanding in children } \\
\text { Department \& Institution: Social SciencelPsychology,Western University } \\
\text { Sponsor: } \\
\text { Ethics Approval Date: December 14, } 2012 \text { Expiry Date: August 31, } 2014\end{array}$} \\
\hline \multicolumn{3}{|c|}{ Documents Reviewed \& Approved \& Documents Received for Information: } \\
\hline Document Name & . & $\begin{array}{l}\text { Version } \\
\text { Date }\end{array}$ \\
\hline Other & $\begin{array}{l}\text { Approval email from TVDSB. We have submitted to them the same } \\
\text { protocol submitted here, including LOI, consent forms and assent. }\end{array}$ & $2012 / 10 / 11$ \\
\hline \multicolumn{3}{|l|}{$\begin{array}{l}\text { Western University } \\
\text { Protocol }\end{array}$} \\
\hline Assent & Both Assent 3-5 and 7-9 & $2012 / 11 / 26$ \\
\hline $\begin{array}{l}\text { Letter of } \\
\text { Information }\end{array}$ & & $2012 / 11 / 26$ \\
\hline
\end{tabular}

This is to notify you that The University of Western Ontario Research Ethics Board for Non-Medical Research Involving Human Subjects (NMREB) which is organized and operates according to the Tri-Council Policy Statement: Ethical Conduct of Research Involving Humans and the applicable laws and regulations of Ontario has granted approval to the above named research study on the approval date noted above.

This approval shall remain valid until the expiry date noted above assuming timely and acceptable responses to the NMREB's periodic requests for surveillance and monitoring information.

Members of the NMREB who are named as investigators in research studies, or declare a conflict of interest, do not participate in discussions related to, nor vote on, such studies when they are presented to the NMREB.

The Chair of the NMREB is Dr. Riley Hinson. The NMREB is registered with the U.S. Department of Health \& Human Services under the IRB registration number IRB 00000941.

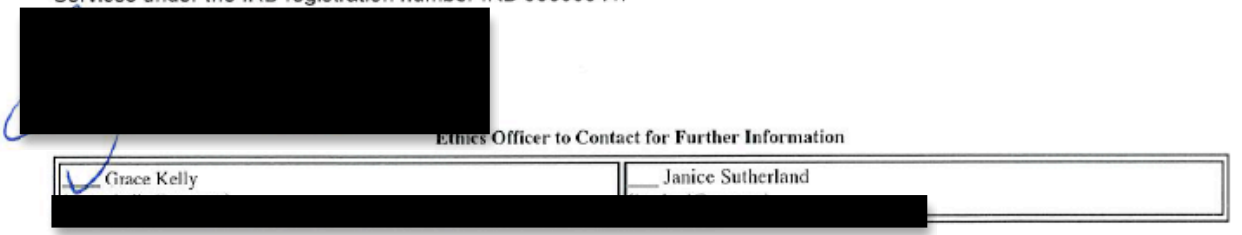

This is an official document. Please retain the original in your files. 
October 52012

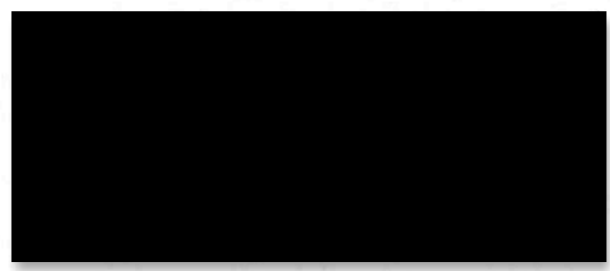

Dear Dr. Joanisse:

Your project, entitled "Predicting reading ability with spoken language understanding in children and adults" has been approved by Operations Services at the Thames Valley District School Board. Information about the study will be sent to school principals and those who are interested in having their school participate in the study will be asked to contact you directly.

As you are no doubt aware, the continued willingness of our faculty to participate in these studies is greatly enhanced by pertinent feedback of findings. I would suggest, therefore, that you make definite plans to provide the appropriate feedback to the school(s) involved. The system also expects a copy of your final report for our research files.

Best of luck with your study. If I can be of further assistance, please feel free to call me.

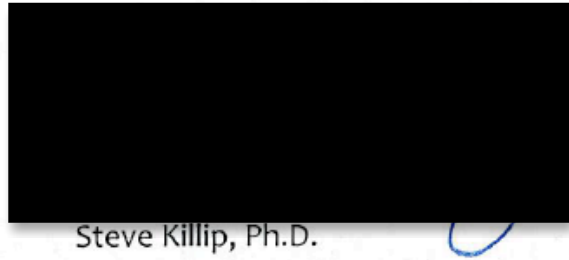

Manager - Research and Assessment Services

Thames Valley District School Board

/sd

cc: K. Wilkinson, Superintendent of Education

\section{Thames Valley District School Board ～- Research and Assessment}




\section{Western University Health Science Researeh Ethics Board} NMREB Annual Continuing Ethics Approval Notice

Date: January 30, 2015

Principal Investigator: Prof. Marc Joanisse

Department \& Institution: Social Science Psychology,Western University

NMREB File Number: 103169

Study Title: Predicting reading ability with spoken language understanding in children Sponsor:

NMREB Renewal Due Date \& NMREB Expiry Date:

Renewal Duc -2015/11/30

Expiry Date -2015/12/14

The Western University Non-Medical Rescarch Ethics Board (NMREB) lhas reviewed the Continuing Fihies Review (CER) form and is re-issuing approval for the above noted study.

The Western University NMREB operates in compliance with the Tri-Council Policy Statenent Ethical Conduct for Research Involving Humans (TCPS2), Part 4 of the Natural Health Product Regulations, the Ontario Freedom of Information and Protection of Privacy Act (FIPPPA, 1990), the Ontario Personal Health Information Protection Act (PHIPA, 2004), and the applicable lavs and regulations of Ontario.

Members of the NMREB who are named as Investigators in research studies do not participate in discussions related to, nor rote on such studies ivhen they are presented to the REB.

The NMREB is registered with the U.S. Department of Health \& Human Services under the IRB registration number IRB OOnONOQd4

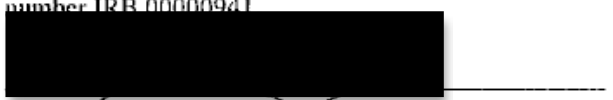

Eithics, Officer, on bchalf dy Yrof. Riicy Hinson, NMREB3 Chair

Ethics Officer to Contact for Further Information

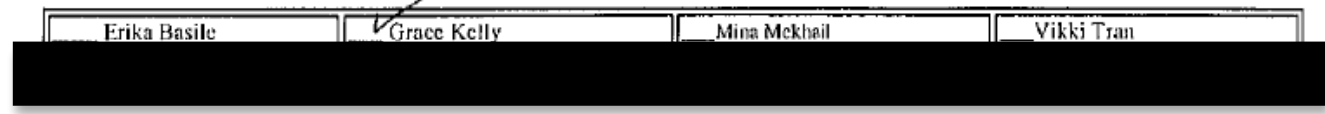

This is an official document. Please retain the original in your files. 
Western University Health Science Research Ethics Board NMREB Amendment Approval Notice

Principal Investigator: Prof. Marc Joanisse

Department \& Institution: Social Science Psychology,Western University

NMREB File Number: 103169

Study Title: Predicting reading ability with spoken language understanding in children Sponsor:

NMREB Revision Approval Date: October 28, 2014

NMREB Expiry Date: August 31, 2015

Documents Approved and/or Received for Information:

\begin{tabular}{l|l|l|}
\hline Document Name & Comments & $\begin{array}{l}\text { Version } \\
\text { Date }\end{array}$ \\
\hline \begin{tabular}{l|l} 
Instruments \\
Instruments
\end{tabular} & sample stimulus array for the RAN task & $2014 / 09 / 21$ \\
\hline $\begin{array}{l}\text { Revised Caregiver Letter of Information \& } \\
\text { Consent }\end{array}$ & sample stimulus array for the digits RAN task & $2014 / 09 / 21$ \\
\hline Revised Western University Protocol & & $2014 / 09 / 22$ \\
\hline Assent & $\begin{array}{l}\text { Consent Form / Assent Form Age 3-5/ Assent Form } \\
\text { Age 7-9 }\end{array}$ & $2014 / 10 / 21$ \\
\hline & &
\end{tabular}

The Western University Non-Medical Science Research Ethics Board (NMREB) has reviewed and approved the amendment to the above named study, as of the NMREB Amendment Approval Date noted above.

NMREB approval for this study remains valid until the NMREB Expiry Date noted above, conditional to timely submission and acceptance of NMREB Continuing Ethics Review,

The Western University NMREB operates in compliance with the Tri-Council Policy Statement Ethical Conduct for Research Involving Humans (TCPS2), the Ontario Personal Health Information Protection Act (PHIPA, 2004), and the applicable laws and regulations of Ontario.

Members of the NMREB who are named as Investigators in research studies do not participate in discussions related to, nor vote on such studies when they are presented to the REB.

The NMREB is registered with the U.S. Department of Health \& Human Services under the IRB registration
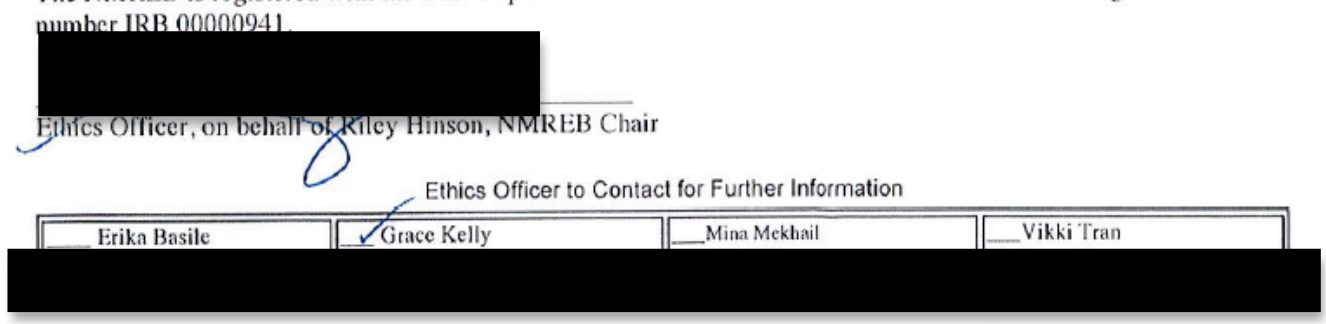

This is an official document. Please retain the original in your files. 


\author{
Principal Investigator: Dr. Marc Joanisse \\ File Number: 103169 \\ Review Level:Delegated \\ Protocol Title: Predicting reading ability with spoken language understanding in children \\ Department \& Institution: Social SciencelPsychology,Western University \\ Sponsor: \\ Ethics Approval Date:December 09, 2013 Expiry Date: August 31, 201 \\ Documents Reviewed \& Approved \& Documents Received for Information:

\begin{tabular}{|l|l|l|}
\hline Document Name & Comments & Version Date \\
\hline Revised Study End Date & &
\end{tabular}

This is to notify you that The University of Western Ontario Research Ethics Board for Non-Medical Research Involving Human Subjects (NMREB) which is organized and operates according to the Tri-Council Policy Statement: Ethical Conduct of Research Involving Humans and the applicable laws and regulations of Ontario has granted approval to the above referenced revision(s) or amendment(s) on the approval date noted above.

This approval shall remain valid until the expiry date noted above assuming timely and acceptable responses to the NMREB's periodic requests for surveillance and monitoring information.

Members of the NMREB who are named as investigators in research studies, or declare a conflict of interest, do not participate in discussions related to, nor vote on, such studies when they are presented to the NMREB.

The Chair of the NMREB is Dr. Riley Hinson. The NMREB is registered with the U.S. Department of Health \& Human Services
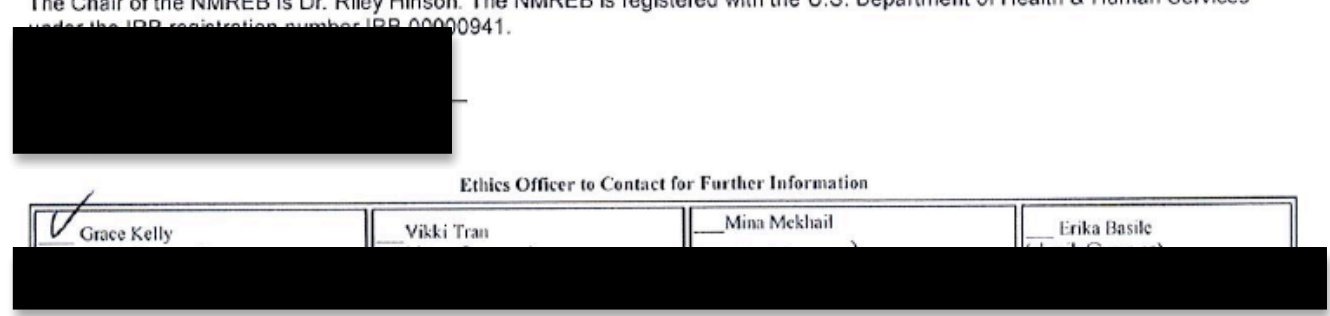

This is an official document. Please retain the original in your files. 


\section{Curriculum Vitae}

\section{Alexandra Mackenzie Cross}

\section{Education}

2015 M.Sc. Psychology, University of Western Ontario, London, Ontario, Canada Advisor: Dr. Marc Joanisse

2013 B.Sc.H. Psychology, Queen's University, Kingston, Ontario, Canada Advisor: Dr. Ingrid Johnsrude

2012 Bilateral Exchange Program (as part of B.Sc.H. Psychology), Victoria University of Wellington, Wellington, New Zealand

\section{Honours Awarded}

2014 Western Graduate Research Scholarship

2013 Western Graduate Research Scholarship

2012 Health and Disability Intelligence Prize in Statistics, Victoria University of Wellington

2009 Queen's University Excellence Scholarship

\section{Professional Experience}

2013-15 Teaching Assistant, University of Western Ontario

2012-13 Teaching Assistant, Queen's University

2011-13 Research Assistant, Queen's University

\section{Peer-Reviewed Posters}

Cross, A.M. \& Joanisse, M.F. (2015). Eyetracking of coarticulatory cue responses in children and adults. Poster presented at the Lake Ontario Visionary Establishment 44th annual meeting, Niagara Falls, Canada. February 2015. 